\title{
ANÁLISIS DE LA APLICACIÓN DEL DERECHO EXTRANJERO A LA LUZ DE LAS DISPOSICIONES GENERALES DE DERECHO INTERNACIONAL PRIVADO EN EL NUEVO CÓDIGO CIVIL Y COMERCIAL ARGENTINO
}

Adriana Margarita Porcelli ${ }^{1}$

\begin{abstract}
Resumen
El Nuevo Código Civil y Comercial de la Nación Argentina, vigente desde agosto del 2015, incorporó, en su articulado, disposiciones específicas de Derecho Internacional Privado-en el Título IV del Libro Sextoculminando un proceso de más de cuarenta años respondiendo a la necesidad de legislar autónomamente esta rama del Derecho, reconociendo su autonomía material, ampliamente pregonada por la doctrina nacional e internacional. El objetivo del presente trabajo consiste en el análisis de la aplicación del derecho extranjero en el Código Civil y Comercial Argentino, así como una breve relación a las normas de fuente convencional. Dada su complejidad, abordarla en forma exhaustiva excede este artículo, por tanto, se presentan los dos aspectos centrales a resolver, las diferentes posturas doctrinarias y su nuevo tratamiento en el Sistema Jurídico Argentino. La metodología se basó en el análisis comparativo de la temática en la doctrina y jurisprudencia argentina y extranjera, su recepción en el nuevo Código Civil y Comercial, en contraposición con su regulación anterior y breves referencias a las normas de fuente convencional. Finalmente se destaca el importante aporte de esta reforma, el diálogo de fuentes y la recepción de las modernas tendencias flexibilizado la elección rígida de la norma de conflicto.
\end{abstract}

Palabras claves: Código Civil y Comercial - Derecho Internacional Privado - Aplicación del Derecho Extranjero Cláusula de Excepción.

\section{INTRODUCCIÓN}

El Código Civil y Comercial de la Nación, puesto en vigencia en Argentina desde el $1^{\circ}$ de agosto del 2015 por las leyes $\mathrm{N}^{\circ} 26.994$ y $\mathrm{N}^{\circ}$ 27.077, vino a unificar en una misma legislación y en un único cuerpo jurídico, las dos grandes codificaciones decimonónicas -reformadas parcialmente con anterioridad- de Derecho Privado.

En virtud del Decreto 191/2011 del Poder Ejecutivo Nacional se puso en marcha un proceso de reforma del Código Civil y unificación con el Código de Comercio a través de la conformación, en febrero de 2011, de una Comisión Redactora integrada por los más prestigiosos doctrinarios y juristas argentinos: el Dr. Ricardo

\footnotetext{
${ }^{1}$ Magíster en Relaciones Internacionales (Universidad Maimónides). Cursando la Actualización en Derecho Informático (UBA). Miembro de Comisiones de Plan de Estudio de las carreras de Ingeniería Agronómica y Tecnicatura Universitaria en Inspección de Alimentos y del Comité Académico de Bioética (Universidad Nacional de Luján). E-mail: adporcelli@yahoo.com.ar
} 
Lorenzetti- Presidente de la Corte Suprema de Justicia de la Nación-, la Dra. Elena Highton de Nolasco- miembro de la Corte Suprema de Justicia de la Nación- y la Dra. Aída Kemelmajer de Carlucci- ex-integrante de la Suprema Corte de la Provincia de Mendoza-. Dicha Comisión designó como Secretario al Dr. Federico De Lorenzo y convocó a distintos sectores de la sociedad y a más de cien profesores para que hicieran llegar sus primeros aportes conforme sus especialidades.

(HERRERA \& LAFFERRIERE, 2012, p.16)

El sustituido Código Civil de Vélez Sarsfield fue el acto de codificación más importante que se dio en el siglo XIX. Con una vigencia de más de cien años, constituyó una regulación pionera, un Código extraordinario a la altura de su época, que supo dar respuestas a una Argentina que crecía y que se inscribía en el mundo. En esa época casi no se hablaba de los temas específicos de Derecho Internacional Privado- salvo del orden público internacional- porque no se percibía su desarrollo, era un Derecho rudimentario y en formación. En consecuencia, dicho Código no contenía una regulación integral y sistemática del Derecho Internacional Privado. Sus normas, muchas veces contradictorias, destinadas a regular relaciones privadas internacionales en materias específicas, estaban dispersas y aisladas a lo largo de su articulado y con importantes categorías no reglamentadas. Las mismas consistían no solo en la determinación del derecho aplicable al fondo del asunto, sino también en la atribución de jurisdicción a los jueces argentinos. Es de destacar que la labor de la doctrina y la jurisprudencia reforzada a través de los casos iusprivatistas fueron llenando las lagunas de este Derecho Internacional Privado. (FERNANDEZ ARROYO, 2014; FERREYRA \& DE ROSAS, 2016)

Pero en el Siglo XXI, se evidenció la necesidad de contar con un instrumento jurídico acorde a las relaciones humanas y comerciales que receptara toda la elaboración doctrinaria y jurisprudencial en este campo del Derecho. En este marco y frente a tales insuficiencias, aunque sin exento de críticas, se sancionó en Nuevo Código Civil y Comercial de la Nación Argentina, culminando un proceso de más de cuarenta años, llevado a cabo por los grandes doctrinarios del Derecho Internacional Privado, a fin de lograr la tan ansiada autonomía normativa. El nuevo Código Civil y Comercial contiene una regulación general y autónoma, aunque incompleta ${ }^{2}$

\footnotetext{
${ }^{2}$ Se afirma incompleta ya que en este cuerpo normativo no se encuentran todas las disposiciones de Derecho Internacional Privado. Se hallan compiladas, al menos la mayoría de sus normas de fuente interna en una sola fuente formal. Al afirmar de fuente interna, se resalta que esta disciplina toma como punto de partida aquellos casos que se vinculan con más de un ordenamiento jurídico estatal y, por este mismo motivo, los tratados o convenciones internacionales han sabido ser una fuente por excelencia del Derecho Internacional Privado, pero esa parte -ahora muy significativa- del sistema no puede estar, por definición, dentro del Código. Por otra parte, no todas las leyes de Derecho Internacional Privado están contenidas en este Código Civil y Comercial ya que no sólo las cuestiones civiles y comerciales -reguladas en el nuevo Código- pueden enmarcarse dentro del contenido de esta materia sino también otras de tipo laboral, penal, notarial, tributario, procesal, navegación aérea y marítima, propiedad intelectual, entre otras. Por tanto, se hace necesario acudir a las respectivas leyes especiales, por ejemplo, sobre sociedades, insolvencia, contrato de trabajo, código aeronáutico, ley de navegación, tributarias y en materia de regulación del arbitraje, sin diferenciar interno o internacional, la encontramos en el Libro Tercero (Derechos Personales) Título IV (Contratos en particular) Capítulo 29 (Contrato de arbitraje). En noviembre de 2016, el Poder Ejecutivo envió un proyecto de ley para incorporar en el ordenamiento jurídico argentino la Ley Modelo de UNCITRAL sobre Arbitraje Comercial Internacional. Además, un sector muy importante del
} 
del Derecho Internacional Privado Argentino en sus últimos setenta y siete artículos, en el Libro Sexto (Disposiciones comunes a los derechos personales y reales) Título IV( Disposiciones de derecho internacional privado ) divida en tres capítulos: Capítulo 1 (Disposiciones generales) del artículo 2594 al 2600, Capítulo 2 (Jurisdicción Internacional) comprende los artículos 2601 al 2612 y Capítulo 3 (Parte especial), más extenso, del artículo 2613 al 2671.

Una de las cuestiones propias de esta rama del derecho es el tema de "aplicación del derecho extranjero", la cual" nos enfrenta a una contradicción fundamental entre el sistema del foro y el sistema extranjero, pues ambos son ordenamientos jurídicos con un tratamiento procesal diferente" (FERNÁNDEZ ROZAS \& SÁNCHEZ LORENZO, 2011, p. 154). El anterior Código- el Código de Vélez-, contemplaba la problemática, en un único artículo (art.13), tomando como fuente a Story- doctrina anglosajona- desde una óptica muy criticada por la doctrina internacionalista.

El presente trabajo abordará específicamente el artículo 2595 (Aplicación del derecho extranjero), pero se debe recordar la especificidad de esta disciplina jurídica, acercando al lector una conceptualización de esta rama del derecho, así como una caracterización de las normas típicas de esta disciplina.

\section{CONCEPTO Y NORMAS DE DERECHO INTERNACIONAL PRIVADO}

El Título IV del Libro VI, inaugura, con el artículo 2594 (Normas aplicables), las Disposiciones Generales de Derecho Internacional Privado. Si bien este artículo establece el orden de prelación de las fuentes, en este punto, el presente trabajo se centra en la primera frase de su articulado. La norma textualmente reza: "Las normas jurídicas aplicables a situaciones vinculadas con varios ordenamientos jurídicos nacionales..." Este artículo reconoce su fuente en el artículo $1^{\circ 3}$ de la Convención Interamericana sobre Normas Generales de Derecho Internacional Privado (CIDIP II, Montevideo, 1979) ${ }^{4}$

Para muchos internacionalistas como All, Albornoz, Perugini Zanetti (2012) $)^{5}$, entre otros, hubiera sido mejor hablar de "relaciones jurídicas", o de "situaciones y relaciones" en el sentido de abarcar no solo la posición

Derecho Internacional Privado autónomo, como ser el que se ocupa de establecer los mecanismos y las condiciones para que las decisiones extranjeras puedan tener efectos en Argentina, se interpretó que, por mandato constitucional, su regulación formaba parte de las atribuciones legislativas provinciales. En consecuencia, cada Código Procesal Privado provincial y federal son los que contienen las normas respectivas.

${ }^{3}$ Dicho artículo, en la parte que aquí interesa analizar, expresa lo siguiente: "La determinación de la norma jurídica aplicable para regir situaciones vinculadas con derecho extranjero se sujetará a lo establecido en esta convención y demás convenciones internacionales ..."

${ }^{4}$ Esta Convención está vigente en Argentina por la Ley 22.921 de 1983 y vincula a dicho país con Brasil, Colombia, Ecuador, Guatemala, México, Paraguay, Perú, Uruguay y Venezuela.

${ }^{5}$ La visión de los autores se puede consultar en PERUGINI ZANETTI, Alicia Panorama general del Capítulo I del Título IV del Proyecto de Código Civil y Comercial de la Nación. In: LAFFERRIERE, J. (comp.) Análisis del proyecto de nuevo Código civil y comercial 2012: informe especial de la Facultad de Derecho de la Pontificia Universidad Católica Argentina. (pp.659-684) 1a ed. - 
del sujeto en relación a sus derechos y deberes -situación- sino también el despliegue efectivo de sus conductas, activas y pasivas, en interacción con otros sujetos dentro de una relación social regulada por el derecho.

Además, la expresión "tratados y convenciones internacionales", que no tiene la Convención Interamericana, no presentan diferencias significativas en el Derecho Internacional Público, son vocablos similares. En definitiva, y más allá de los problemas de redacción apuntados, las normas de Derecho Internacional Privado entran en juego cuando el caso posee al menos un elemento relevante situado en un Estado extranjero.

A lo largo de la historia se han dado múltiples definiciones de Derecho Internacional Privado, sin embargo, preferimos, siguiendo las enseñanzas de la Profesora Biocca afirmar que:

... la noción, que hace más flexible el concepto y el objeto de una rama del Derecho. Por eso decimos que el Derecho Internacional Privado es aquel que comprende las relaciones jurídicas que tienen un elemento ostensible u oculto, extraño al derecho local, sin analizar previamente su naturaleza esencial, no importa que ella sea de carácter civil, comercial o penal; es suficiente que el interés comprometido sea de una persona privada y que a su respecto se plantee el problema de la ley que la reglamenta y de la jurisdicción competente (BIOCCA et al, 1997, p.20)

De esta noción distinguimos los siguientes elementos:

1. Una relación privada que se practica o constituye en varios países, o sea es de carácter multinacional. Una relación es internacional cuando no tiene todos sus elementos nacionales y afecta a más de un Estado ${ }^{6}$.

2. Que el caso aparece ligado o tiene conexión con dos o más sistemas jurídicos nacionales diversos.

3. Que cada Estado reclama para sí el ejercicio de su potestad jurisdiccional sobre las controversias que caen bajo su ámbito de validez estatal, por lo cual es necesario determinar el país con el cual se relaciona esencialmente, a pesar de sus múltiples relaciones con otros. A esa relación esencial se le reconoce una suerte de poder centralizador, localizador del caso.

La hipótesis es la de una relación que está vinculada con dos o más ordenamientos jurídicos que, como lógicamente no pueden aplicarse todos a la vez, queda sometida a uno de ellos. El problema inmediato que surge es el del mecanismo para elegir tal derecho y jurisdicción, para lo cual, el Derecho Internacional Privado, se vale de diferentes tipos de métodos y de normas- pluralismo normativo y metodológico ${ }^{7}$-, a saber:

1. Norma indirecta, también denominada regla de conflicto, norma de remisión o norma de

Buenos Aires, Argentina: El Derecho, 2012, 695 p.

${ }^{6}$ Por ejemplo: la restitución internacional de niños a su lugar de residencia habitual, el Teletrabajo desde el hogar, un consumidor desde su domicilio adquiere por internet un bien y lo recibe con vicios que lo hacen defectuoso para su uso, un turista adquiere un viaje al extranjero por un precio global que comprende prestaciones combinadas de transporte y alojamiento, una persona fallece en el país y deja bienes en el extranjero, una sociedad establece agencias o sucursales fuera del Estado en el cual está su domicilio o realiza diversos actos o posee bienes en otros Estados, una letra de cambio librada en un país es pagadera en otro y puede ser endosada en terceros Estados, una empresa situada en un país realiza una actividad productiva y produce daños por contaminación transfronteriza, una persona comete en un Estado un delito que se consuma en otro, una sentencia necesita ser ejecutada en un Estado distinto al del tribunal del cual emana.

${ }^{7}$ Para ampliar sobre el tema véase: UZAL, María Elsa. El pluralismo en el Derecho Internacional Privado como una necesidad Metodológica. El Derecho. Tomo 161, 1995, p. 1056-1063. 
Derecho Internacional Privado, la cual indica o remite al Derecho que en definitiva resolverá la controversia, por lo cual el método es el indirecto, analítico-analógico o conflictual.

2. Norma directa, también denominada norma material, sustancial o de Derecho Privado, que resuelve ella misma la controversia, en consecuencia, el método es directo o material.

3. Norma internacionalmente imperativa, de aplicación inmediata, necesaria o normas de policía, como se vale del derecho nacional, el método que se sigue es el unilateral.

A mediados de la década del 60, autores franceses, entre ellos Francescakis (1966), observaron que, en la práctica de los tribunales de su país y pese a lo establecido por las normas indirectas o reglas de conflicto generales, ciertas normas y reglamentos de la lex fori (ley del juez)- en virtud de su contenido sustancial y de sus características- eran inmediatamente aplicadas a la solución de los casos multinacionales. El legislador, por razones de orden social, político, económico o temas en que está especialmente interesado en resguardar, autoelige o autoselecciona su propio derecho para ser aplicado, no remite la solución (como haría el método indirecto) sino que aplica su propio derecho sustancial. A estas normas, dicho autor, las denominó "leyes de aplicación inmediata o normas de policía”. Son normas especiales, excepcionales, generalmente de fuente interna creadas por el legislador nacional según la realidad y circunstancias de su Estado y que optan por rechazar a priori cualquier solución que no sea basada en sus principales convicciones jurídicas. (BOGGIANO, 2011, p.73,74)

Si bien es ampliamente reconocido este pluralismo normativo adoptado por el legislador argentino, la norma indirecta sigue siendo la más numerosa y típica del Derecho Internacional Privado tanto de fuente interna como de fuente internacional o convencional.

\section{APLICACIÓN DEL DERECHO EXTRANJERO}

Para el desarrollo de esta temática propia y específica de Derecho Internacional Privado el análisis se centra en una controversia internacional a resolver. Se destaca que la temática de la Aplicación del Derecho Extranjero, como las demás cuestiones típicas de esta rama del Derecho, se plantean por la estructura de la norma indirecta, ya que, si el Derecho Internacional Privado se valiese únicamente de normas directas, la problemática desarrollada en el presente trabajo no se presentaría. El juez competente argentino deberá consultar, en primer lugar, si existe un Tratado Internacional aplicable al caso, en su defecto al Derecho Interno Argentino ${ }^{8}$ y, siempre que el caso objeto de litigio no se resuelva por la aplicación de una norma directa, aplicará su norma indirecta o de conflicto la cual le indica el Derecho que resolverá la cuestión. Si declara aplicable el propio Derecho Privado del juez que entiende en la causa- la lex fori, la situación será resuelta en el ámbito del Derecho propio y por esa razón

\footnotetext{
${ }^{8}$ Conforme el artículo 75 inciso 22 de la Constitución Argentina y el artículo 2594 del Código Civil y Comercial de la Nación Argentina, los Tratados Internacionales tienen jerarquía superior a las leyes, jerarquía supralegal
} 
es una norma que no presenta dificultad porque lo remite al sistema de Derecho donde el juez está capacitado y el cual conoce. En cambio, si la regla de conflicto declara aplicable al Derecho extranjero, se presenta la problemática de la calidad del Derecho extranjero aplicable, es decir se refiere a la manera en que debe aplicarse ese ordenamiento jurídico extranjero indicado por la norma conflictual.

El artículo 2595 (Aplicación del derecho extranjero) establece una regla de aplicación del Derecho extranjero. Se trata de una visión superadora en comparación con la adoptada por el anterior Código de Vélez que, en el artículo 13, contemplaba la problemática tomando como fuente a Story- doctrina anglosajona- desde una óptica muy criticada por la doctrina internacionalista. El mismo afirmaba "la aplicación del derecho extranjero en los casos en que este Código lo autoriza, nunca tendrá lugar sino a solicitud de parte interesada, a cuyo cargo será la prueba de la existencia de dichas leyes. Exceptúense las leyes extranjeras que se hicieren obligatorias en la República por convenciones diplomáticas" dando lugar a tres interpretaciones diferentes. Una literal, otra propiciaba su negación y una intermedia restrictiva que interpretaba el vocablo "autoriza", sosteniendo que cuando el Código imponía la aplicación del Derecho extranjero, debía serlo de oficio, y cuando la autorizaba debería alegarse y probarse. Si las partes no le probaban al juez argentino el contenido del Derecho extranjero, significaba que el juez aplicaba su propio Derecho Privado interno, lo que transformaba todas las reglas de conflicto en facultativas y no obligatorias. (LAZCANO, 1965, p.134) Posteriormente, tanto la doctrina como la jurisprudencia, fueron elaborando interpretaciones para admitir la aplicación de oficio, acudiendo a diversos argumentos que incluían desde el artículo 377 del Código Procesal Civil y Comercial de la Nación-el cual se desarrollará en el próximo punto-hasta las diferentes reglas adoptadas en las Convenciones InternacionalesTratados de Montevideo de $1889^{9}$ y de $1940^{10}$ y la Convención Interamericana sobre Normas Generales de Derecho Internacional Privado (CIDIP II)- esta última receptada en el actual Código.

A continuación, se explicará brevemente las diferentes posiciones doctrinarias formuladas, presentando la problemática desde su doble vertiente, íntimamente ligadas: la sustancial y procesal:

1. Calidad o naturaleza del Derecho extranjero: esto es si el Derecho extranjero tiene la misma jerarquía que el del juez, es tan Derecho como el nacional o es inferior y es un mero hecho

2. Tratamiento procesal del Derecho extranjero: si su aplicación es de oficio, o por el contrario es a pedido de parte interesada quien debe alegar y probar el Derecho extranjero. La primera responde a considerar el Derecho extranjero como Derecho y la segunda a considerarlo como un hecho.

\footnotetext{
${ }^{9}$ Los Tratados de Montevideo de 1889 son ocho tratados y un Protocolo Adicional, todos aprobados por Argentina por Ley 3.192 que vincula a dicho país con Bolivia, Paraguay, Perú y Uruguay. Actualmente en vigor.

${ }^{10}$ Los Tratados de Montevideo de 1940 son ocho Tratados y un Protocolo Adicional fueron aprobados en su totalidad por Uruguay y Paraguay y actualmente se encuentran en vigor. El Tratado de Derecho Penal Internacional fue desdoblado en dos: el de Derecho Penal Internacional y el de Refugio y Asilo Político En igual manera, el Tratado de Derecho Comercial también fue desdoblado en Comercial Terrestre y Comercial Marítimo. Argentina aprobó por Dec. Ley N 7771/56 y Dec. Ley N 468/63 casi
} 


\section{CALIDAD O NATURALEZA DEL DERECHO EXTRANJERO}

En este aspecto, podemos agrupar en dos grandes teorías:

Teorías Realistas: consideran al Derecho extranjero como un hecho y dentro de ellas:

1. Teoría de la Comitas Gentium o Cortesía Internacional: originada en la Escuela Estatuaria Flamencoholandesa y formulada por Story (1934), perteneciente a la Doctrina Anglosajona y juez de la Corte Suprema de Justicia de Norteamérica, quien mediante el empleo del método inductivo resumió, de las decisiones judiciales, los principios generales que inspiraban la solución de los conflictos de leyes.

Sintetizó las reglas generales de la siguiente manera:

a. Las reglas sobre conflicto de leyes son nacionales.

b. El Derecho extranjero es un hecho.

c. El fundamento a la extraterritorialidad del Derecho radica en la Comitas Gentium, es decir los jueces pueden aplicar el Derecho extranjero por cortesía intencional, entendiendo esta última como una facultad discrecional del juez y no como un deber, ni como una obligación jurídica sino como un acto de conveniencia, de utilidad o si hay reciprocidad (BIOCCA et al, op. cit., p.111)

2. Teoría del Uso Jurídico: desarrollada por Goldschmidt, también denominada sentencia probable del juez extranjero. Dicho autor parte de la base que el mundo jurídico extranjero, como el nacional, también es tridimensional ${ }^{11}$. Sin embargo, cuando la norma indirecta declara aplicable al Derecho extranjero, se refiere únicamente a las dimensiones nomológica -leyes- y sociológica -jurisprudencia y conductas colectivas- del ordenamiento jurídico extranjero aplicable. Descarta la dimensión dikelógica -valores- ya que nos reservamos nuestras propias concepciones. Por lo tanto, para el juez que entiende en la causa, el Derecho extranjero es bidimensional. (GOLDSCHMIDT, 1976, p.16)

Este razonamiento deriva en que, si se declara aplicable a una controversia un Derecho extranjero, hay que darle el mismo tratamiento de fondo que con el mayor grado asequible de probabilidad le daría el juez del país cuyo derecho ha sido declarado aplicable. Dicho con otras palabras, según esta teoría los jueces deben dar un

todos, menos el Tratado de Derecho Penal, el Tratado sobre Refugio y Asilo Político y el Tratado sobre Propiedad Intelectual ${ }^{11}$ Werner Goldschmidt sostuvo que el fenómeno jurídico era una totalidad compleja que denominó 'Mundo Jurídico' y propuso así el estudio del Mundo Jurídico mediante el análisis de los tres grandes elementos que lo integran (conductas, normas y valores) El trialismo sostiene que el mundo jurídico consta de tres dimensiones Integradas, y que cualquier rama de la ciencia jurídica debe reflejar esta Tridimensionalidad El Derecho Internacional Privado es tridimensional, si se mueve en la realidad social, se plasma en normas y se inspira en la justicia. El aspecto nomológico comprende la indicación del contenido de las normas. La dimensión sociológica- comprende la jurisprudencia judicial y administrativa, así como las usanzas v costumbres de los habitantes y la doctrina forma parte de esta dimensión La sección dikelógica, por último, se dedica a la crítica de las normas, de las soluciones y a la elaboración de normas justas. Ver GOLDSCHMIDT, Werner. Introducción filosófica al Derecho - La teoría Trialista del mundo jurídico y sus horizontes. Buenos Aires, Argentina: Depalma, 1976, 665 p. 
tratamiento respetuoso al Derecho extranjero y la manera de realizarlo es no solo aplicando las normas jurídicas extranjeras sino también deben someterse a la interpretación que los jueces extranjeros le dan a su respectivo derecho, para no desnaturalizarlo ni alterarlo con las propias convicciones jurídicas del juez. En realidad, los jueces nacionales no realizan la "aplicación" sino "imitación del derecho extranjero". Textualmente afirma: "aplicamos el Derecho propio; observamos, remedamos, en una palabra: imitamos el Derecho extranjero" (GOLDSCHMIDT, 1990, p.138). El juez debe ubicarse mentalmente en el país cuyo Derecho debía aplicarse e interpretar sus normas como esta autoridad lo haría. Por supuesto que, si se afirma que al Derecho extranjero hay que darle un trato respetuoso, considerarlo un mero hecho contradice el razonamiento, entonces Goldschmidt lo considera como un hecho notorio. Un hecho notorio no es un hecho que todo el mundo conoce sino un hecho que todo el mundo es capaz de averiguar de manera fidedigna. La notoriedad es un conocimiento relativo ya que un hecho puede ser notorio sin ser conocido por todas las personas, lo que lo caracteriza consiste en la capacidad de obtener información del mismo y recibe el mismo tratamiento procesal que las normas jurídicas. (Ibídem, p.137).

Esta teoría reconoce como antecedente el caso "Collier c. Rivaz"(1841), a partir del cual, los tribunales ingleses desarrollaron, desde 1926, la teoría denominada foreign court theory. El juez Herbert Jenner decía, en tal caso: "the court sitting here decides from the persons skilled in that (Belgian) law, and decides as it would if sitting in Belgium." De modo que el juez nacional debe fallar "como lo haría" el juez del país cuyo derecho resulta aplicable. (BOGGIANO, 2011, p.238)

Teorías Jurídicas o Normativistas: consideran al Derecho extranjero como un derecho. Dentro de ellas se pueden diferenciar dos concepciones: A) nacionalización o incorporación del Derecho extranjero y B) la extranjería

1. Nacionalización o Incorporación del Derecho Extranjero al Nacional: exige, para su aplicación extraterritorial, la apropiación o nacionalización del Derecho extranjero al Derecho nacional. En esta corriente ubicamos al resto de la Doctrina Anglosajona, a saber:

a. En Inglaterra, la teoría de la cortesía internacional fue sustituida por la teoría de Vested Rights, es decir derechos revestidos o derechos válidamente adquiridos. Dicey, su autor, parte de la diferencia entre derecho objetivo y derecho subjetivo y establece los siguientes postulados:

i. Como principio indiscutible afirma la territorialidad de la ley, lo que significa que sobre suelo inglés solo se aplica Derecho objetivo inglés, que es el único que debe ser obedecido.

ii. Todo derecho válidamente adquirido bajo una ley de cualquier Estado civilizado debe ser reconocido por la Corte inglesa.

iii. Como excepción al segundo postulado menciona el orden público. (KALLER DE ORCHANSKY, 1997, p.70; BIOCCA et al, op. cit, p.112) 
b. En Estados Unidos: se pueden distinguir dos tendencias

i. Incorporación legislativa de los derechos subjetivos: la teoría de Dicey fue tomada y reformulada por Beale de la Escuela de Harvard. Según dicho autor, para el reconocimiento en Estados Unidos de los derechos adquiridos en el extranjero, deberá corroborarse que los mismos hayan nacido como consecuencia de la aplicación de una ley competente y, de ser así, para que produzcan efectos extraterritoriales deberá existir una ley norteamericana que los reconozca, que es la regla de conflicto nacional. En consecuencia, se recrean los derechos subjetivos adquiridos en el extranjero por su incorporación a través de la regla de conflicto nacional norteamericana. (Ibídem, p.71)

ii. Incorporación judicial del derecho objetivo: sostenida por Lorenzen de la Escuela de Yale, quien critica fuertemente a la teoría de Beale, negando cualquier incorporación de los derechos subjetivos u objetivos extranjeros. La Local Law Theory parte del principio judge made law, utiliza el método empírico -el experimental pragmático- y considera que, cuando el juez norteamericano aplica el Derecho de otro país, en realidad no está aplicando el Derecho de otro Estado, sino que crea un Derecho nacional idéntico o al menos muy semejante a aquel que se encuentra vigente en otro país. (BIOCCA et al, op. cit,, p.113) Pero, aclara, que no se trata de un Derecho local correspondiente a las relaciones jurídicas nacionales, sino otro, creado ex profeso y a posteriori por el juez, cumpliendo así con el postulado territorialista. (KALLER DE ORCHANSKY, op. cit., p.74, 75)

Esta teoría fue continuada hasta nuestros días, basada en un realismo jurídico, una suerte de judicial behaviorism-conductismo judicial-en autores como Cavers, Currie y Ehrenzweig los que avanzaron en la construcción de una nueva teoría general de los conflictos de leyes, reaccionando contra los puntos de conexión rígidos y aplicando criterios flexibles.

Desde 1960, en Estados Unidos, se registró una fuerte reacción doctrinaria, la denominada revolución americana -léase norteamericana- contra los métodos tradicionales, priorizando el sistema jurídico que tuviese las estrechas vinculaciones del caso, apartándose de criterios rígidos predeterminados. Cavers, uno de sus exponentes, en 1965 publica The Choice of Law Process, denomina peyorativamente a la norma conflictual como una norma mecánica. La norma de conflicto, afirma, se parece a la computadora de una oficina de correo ultramoderna que reparte las cartas según el código postal, sin preocuparse en principio de si este reparto corresponde a su verdadero destino. En consecuencia, el juez debe elegir entre las leyes materiales en conflicto, la que conviene mejor al caso en cuestión. Para este autor el conflicto de leyes no debería ser considerado como una superposición de competencias legislativas y se podría decir que el sistema de Cavers se presenta como la búsqueda de la justicia 
material en el caso concreto. Aparece la preocupación por detectar the most closest connexions o the most significant relationships que podía ser seguido por el juez para determinar aquel Derecho que, por su estrecha vinculación con la controversia, sea el indicado para brindar la solución. En este caso se está utilizando un criterio flexible que otorga mayor discrecionalidad al juez, a diferencia del criterio rígido. Esta teoría se encuentra receptada en el Second Restatement of the Conflict of Laws publicado en 1971. (FRESNEDO DE AGUIRRE, 2003a, p.285) y en Argentina, en el artículo 2597. Cláusula de Excepción que será analizada finalizando el trabajo

2. Teoría de la extranjería: considera que el Derecho extranjero no pierde su naturaleza normativa por la circunstancia de la extraterritorialidad, por tanto, se aplica como Derecho y como extranjero, sin pasar por ningún proceso previo de nacionalización, incorporación o apropiación. Su exponente fue Federico Carlos Von Savigny (1849), fuente inspiradora del Código de Vélez Sarsfield. En su obra Sistema de Derecho Romano Actual desarrolló una teoría completa de Derecho Internacional Privado siendo el primer autor en elaborar el fundamento jurídico de la extraterritorialidad del Derecho, reaccionando contra los fundamentos invocados hasta entonces, por ejemplo, de la cortesía internacional de Story. Dicho fundamento jurídico lo basó en la existencia, entre las naciones civilizadas, de una verdadera Comunidad de Derecho o Comunidad Jurídica de las Naciones la cual se debe al contacto frecuente entre los pueblos, a la igualdad entre el nacional y el extranjero y al estado de interdependencia recíproca entre los que han alcanzado un mismo grado de civilización. Esto hace posible que los pueblos admitan los mismos principios por convicciones jurídicas comunes. La Comunidad de Derecho es una forma de solidaridad social que obliga a todos los hombres a respetar recíprocamente sus derechos sin distinción de patrias, como miembros de una misma comunidad que persigue el mismo ideal. La fundamentó en dos grandes pilares que dieron origen al Derecho: el Derecho Romano y el Derecho Canónico. Desarrolló en forma científica el tema del orden público internacional, aunque sin designarlo de esa manera sino como límites a la aplicación del Derecho extranjero o excepciones a la Comunidad de Derecho. (WEINBERG DE ROCA, 1997, p.19; BIOCCA et al, op. cit., p.124, 125)

\section{TRATAMIENTO PROCESAL DEL DERECHO EXTRANJERO}

Este tema presenta una problemática de naturaleza procesal, lo que significa que, cuando la norma indirecta remite al Derecho extranjero, la pregunta radica en saber si el juez tiene la obligación de investigarlo y aplicarlo de oficio, o, por el contrario, debe esperar a que la parte le pida la aplicación y luego le pruebe su texto, vigencia y sentido. A este respecto se formularon tres criterios, dos de ellos perfectamente diferenciados: aplicación a instancia de parte interesada, aplicación de oficio y uno intermedio. 
Aplicación del Derecho Extranjero a Pedido de Parte Interesada

Este criterio lo sostienen los partidarios de la cortesía internacional y de las modernas corrientes que de ella se derivan. Consideran que los Estados no están obligados a aplicar las leyes extranjeras, o sea no es una obligación jurídica y si deciden hacerlo es en virtud de la cortesía internacional, conveniencia y la recíproca utilidad que con ello persiguen. No se aplica el principio iura novit curia, vocablo latino que significa el juez conoce el derecho. (WEINBERG DE ROCA, op. Cit., p.49). Como el Derecho extranjero no es Derecho, es un hecho, recae en las partes la carga procesal probatoria del Derecho extranjero de la misma manera que deben probar los hechos que le relatan al juez. La consecuencia de este criterio es que la parte que alega el Derecho extranjero debe probarlo y no solo el texto sino también el sentido y la vigencia. En ausencia de prueba o si el juez considera que no está suficientemente probado por la parte, no lo aplica, aun cuando hubiere tomado conocimiento del mismo por otros medios.

Entre los países que adoptan este criterio podemos mencionar a: Estados Unidos, Inglaterra, Canadá, Australia.

En Francia tradicionalmente, incumbía a la parte que solicitaba la aplicación de una ley extranjera establecer el contenido de ésta y, más concretamente, demostrar que la aplicación de la Ley Francesa no permitía lograr un resultado equivalente. Según una jurisprudencia relativamente reciente, de 1998, en adelante se admite que el propio juez debe buscar el contenido de la Ley extranjera aplicable, lo que deberá hacer de oficio cuando el litigio de que se trate se refiera a derechos inalienables.

Ahora bien, para este criterio es importante detallar los medios de prueba del Derecho extranjero, y, en base a nuestra jurisprudencia, anterior al Código hoy vigente, se puede mencionar:

1. Copia auténtica de la ley: con certificación oficial de su vigencia y traducción realizada por un traductor oficial.

2. Referencias de obras conocidas: las fuentes de conocimiento, son las obras de los jurisconsultos y doctrinarios para probar el sentido y la vigencia. El acceso a la información, la facilidad de las comunicaciones y la interacción internacional permite hoy en día confiar tanto en el jurista argentino como en el extranjero. El dictamen del especialista tiene una doble función: como medio de prueba del Derecho extranjero aplicable y como opinión solvente sobre la interpretación de ese Derecho.

3. Jurisprudencia: también en cuanto a la aplicación práctica del Derecho extranjero. La jurisprudencia no sólo reviste especial significación para el conocimiento del Derecho de países pertenecientes al common law, sino que suponen asimismo un importante aporte para informar acerca de la interpretación y aplicación de la normativa de los Estados de Derecho escrito. 
4. Atestación de escribano extranjero: en los documentos solemnes, es prueba suficiente de la observancia de la ley allí vigente.

5. Informe consular: reviste importancia para probar la vigencia y el sentido del ordenamiento jurídico extranjero, pero la jurisprudencia argentina anterior al dictado del Código Civil y Comercial, estableció que no puede suplir el texto de la ley.

6. Intercambio recíproco de información entre los Estados: se trata de un procedimiento informativo, habiéndose trasformado a nivel regional en el método más utilizado para comunicar con exactitud y objetividad el Derecho foráneo. Esta actividad, a cargo del Estado, exige la puesta en funcionamiento de organismos capaces de llevarla a cabo, dotándolos de personal técnico capacitado para el correcto cumplimiento de sus cometidos. Este mecanismo está previsto en los Tratados de Montevideo de 1889 y de 1940, en la Convención Interamericana sobre Normas Generales de Derecho Internacional Privado (CIDIP II) y en las demás convenciones que se analizarán al desarrollar el tema de la aplicación del Derecho extranjero de fuente convencional. La Convención de Bruselas sobre el Canje de Publicaciones Oficiales y Documentos Gubernamentales entre Estados de $1958^{12}$, no ratificada por Argentina, obliga a los Estados partes a canjear los diarios oficiales, documentos, informes y anales parlamentarios, las publicaciones e informes de carácter administrativo, las bibliografías nacionales, los repertorios administrativos, los repertorios de leyes y jurisprudencia, entre otros. En cada Estado contratante, el canje correrá a cargo del servicio nacional de canje o, si éste no existiere, de la autoridad o autoridades centrales designadas al efecto. Las autoridades encargadas del canje en los Estados contratantes fijarán, de común acuerdo, la lista y el número de las publicaciones oficiales y documentos gubernamentales destinados al mismo.

7. Información proporcionada por Instituciones especializadas como el Max Planck de Hamburgo, que además de las publicaciones tiene grupos de especialistas por regiones y materias que expiden informaciones sobre el Derecho de diferentes países. La Unión Internacional del Notariado Latino ${ }^{13}$ creó la Oficina Notarial Permanente de Intercambio Internacional -ONPI- con sede en Buenos Aires, la

\footnotetext{
${ }^{12}$ La Convención de Bruselas no fue ratificada por Argentina, por eso no forma parte del derecho argentino. Los Estados ratificantes son: Alemania, Arabia Saudita, Australia, Belarús, Bélgica, Brunei, Bulgaria, China, Cuba, Dinamarca, República Dominicana, Ecuador, Egipto, Eslovaquia, España, Estados Unidos de América ,Estonia, Federación de Rusia, Finlandia, Francia, Georgia, Ghana, Guatemala, Hungría ,Indonesia, Iraq, Islas Salomón, Israel, Italia, Japón, Libia, Lituania, Luxemburgo, Malta, Marruecos, Nigeria, Noruega, Nueva Zelandia, Países Bajos, Panamá, Polonia, Reino Unido de Gran Bretaña e Irlanda del Norte ,República Centroafricana, República Checa, Rumania, San Vicente y las Granadinas, Sri Lanka, Suecia Tayikistán, Ucrania

${ }^{13}$ La Unión Internacional del Notariado-UINL- es una organización no gubernamental constituida para promover, coordinar y desarrollar la actividad notarial en todo el mundo y para proteger la dignidad e independencia de los distintos Notariados. Fue Fundada en 1948 en Buenos Aires donde se encuentra su sede La Unión cuenta actualmente con setenta países miembros, la mayoría de los países de la Unión Europea y Latinoamérica, todos los países del Este de Europa, Japón y muchos de Asia y África (recientemente se dio de baja el notariado de Sudáfrica e ingresaron los notariados de Moldavia, Macedonia y República de Chad).
} 
que tiene la finalidad de mantener informados a los países miembros de la Unión de los Derechos vigentes. Las informaciones suelen estar en la Revista Internacional del Notariado Latino.

8. Las nuevas tecnologías de la información y comunicación -TICs- en especial Internet, son una de las principales fuentes para proporcionar información del Derecho extranjero en nuestros días. La Informática Jurídica permite almacenar y recuperar en forma ubicua, sincrónica e instantánea los datos jurídicos. Si, además, el contenido del banco de datos abarca no solo las normas, sino la jurisprudencia y la doctrina, la información puede ser muy completa. Al respecto cabe recordar que en 1981 fue inaugurado el Sistema Argentino de Informática Jurídica -SAIJ-. Se trata de un banco de datos que almacena los documentos jurídicos y funciona en el ámbito del Ministerio de Justicia y Derechos Humanos de la Nación Argentina. (PERUGINI ZANETTI, 2012, p.666-668)

\section{APLICACIÓN DEL DERECHO EXTRANJERO DE OFICIO}

Esta postura la sustentan los partidarios de considerar al Derecho Extranjero como Derecho y como extranjero- que con tanto rigor científico formulara Savigny- y los que afirman que el Derecho extranjero es un hecho notorio- tesis elaborada por Goldschmidt y receptada en varias convenciones internacionales- ya que, un hecho notorio recibe el mismo tratamiento procesal que las normas jurídicas. En virtud de este criterio, el principio iura novit curia es entendido con diferente alcance según se trate del Derecho nacional o extranjero. En el primer caso como deber de conocimiento, pero en el segundo como deber de información ya que existe una imposibilidad fáctica del juez de conocer todos los derechos del mundo. Entonces el juez está obligado a aplicar el Derecho extranjero, sobre el cual debe informarse personalmente sin perjuicio que las partes puedan facilitar esa misión informativa del juez por todos los medios de prueba arriba enumerados. Del mismo modo que las partes se empeñan en interpretar y demostrar el alcance y sentido del Derecho nacional, se han de esforzar en interpretar y demostrar el alcance y sentido del Derecho extranjero. La diferencia fundamental es que, en la aplicación de oficio, la obligación se encuentra en cabeza del juez competente, las partes pueden colaborar, pero si no lo hacen, el juez tiene la obligación de aplicar el Derecho extranjero y no es excusa la falta de prueba. (FRESNEDO DE AGUIRRE, op. cit., p. 263, 264) Actualmente, la mayoría de los países fueron adoptando este criterio, a saber: Austria, Alemania, Hungría, Venezuela, España, Turquía, Grecia, Suiza, Perú, Italia, Paraguay, Países Bajos y Portugal- que trata al Derecho extranjero como Derecho, el juez debe, de oficio, intentar obtener información sobre el contenido cuando la parte no lo haya podido probar. México, evolucionó hacia la aplicación de oficio, ya que el sistema procesal mexicano que, tradicionalmente aceptaba el principio de instancia de parte, fue objeto de modificación y ahora, tanto el artículo 14 del Código Civil para el Distrito Federal de 1988 como el 86 bis del Código Federal de Procedimientos Civiles de 1988 disponen que se aplique como lo haría el juez extranjero. En 
Uruguay, la jurisprudencia admite la aplicación del Derecho extranjero de oficio y el artículo 2 del Proyecto de Ley General de Derecho Internacional Privado uruguayo, establece que el mismo es Derecho y está obligado a interpretarlo tal como lo harían los jueces del Estado al que pertenece la norma. ${ }^{14}$

\section{SISTEMA INTERMEDIO}

Este sistema parte de la base que las normas jurídicas extranjeras vigentes en un Estado deben ser probadas por las partes solo cuando sean desconocidas por el juez. Para la aplicación de tales normas, el tribunal no está obligado a limitarse a las pruebas proporcionadas por las partes, sino que puede valerse también de otras fuentes de información. El principio general es la aplicación de oficio del Derecho extranjero por parte del juez en la medida en que éste le sea conocido, por el contrario, si el tribunal lo desconoce, puede requerir su prueba a las partes y valerse de otra información. (PARRA ARANGUREN, 1971, p.44)

\section{RECURSO DE EXTRAORDINARIO Y DE CASACIÓN}

Un aspecto que también ha dado lugar a posiciones encontradas referidas a la temática procesal de la aplicación del derecho extranjero estriba en si se admite o no la posibilidad de interponer un recurso de apelación, de casación o recurso extraordinario frente a la aplicación errónea, incorrecta del Derecho extranjero o directamente frente a la ausencia de aplicación del mismo por parte del juez de primera instancia. Los recursos procesales son esos medios técnicos que las legislaciones ponen a disposición de los sujetos de derecho para impugnar las decisiones judiciales. Con ellos se pretende subsanar los errores o vicios en que eventualmente se haya incurrido al dictarlas, mediante la revisión del fallo por el mismo tribunal que lo dictó o por otro de superior jerarquía. Los recursos tienden a controlar la legalidad y la justicia de las decisiones judiciales.

Al respecto, se pueden diferenciar tres tesis:

1. Tesis clásica o negativa: asimila el Derecho extranjero a una cuestión de hechoy, por consiguiente, plantea la improcedencia del recurso en los casos de infracción o incorrecta aplicación judicial de las normas del Derecho foráneo, con el argumento fundamental de que la casación no conoce de los hechos sino del Derecho. La violación de una ley extranjera no es motivo de casación, su interpretación, como la de cualquier otra cuestión de hecho, corresponde a la soberanía de los jueces de instancia y no es revisable en casación. (CALVO CARAVACA \& CARRASCOSA GONZÁLEZ, 2005, p. 267-280) Los argumentos sobre los que esta tesis se edifica son los siguientes:

\footnotetext{
${ }^{14}$ Todas estas leyes se pueden consultar en la Red Judicial Europea en materia civil y comercial. COMISIÓN EUROPEA. Red Judicial Europea en materia civil y comercial. Recuperado el 25 de noviembre de 2016 desde http://ec.europa.eu/civiljustice/applicable_law/applicable_law_spa_es.htm
} 
a. El Derecho extranjero es un hecho procesal, y visto que los hechos no se revisan en casación, la casación por infracción del Derecho extranjero es imposible.

b. El objetivo del recurso de casación es mantener una uniformidad de la jurisprudencia. Por tanto, no cabe para interpretar un Derecho extranjero.

c. De aceptarse ese recurso por infracción del Derecho extranjero, podrían producirse contradicciones entre la interpretación dada por el Tribunal Superior nacional y la sostenida por los jueces extranjeros sobre el Derecho extranjero. (FERNANDEZ ROZAS, 1995, p.1046-1048)

2. Tesis moderna o positiva: La doctrina moderna combate categóricamente la posición clásica por ilógica, porque cuando el legislador ordena, por su regla de conflicto, la aplicación de un Derecho Extranjero, es indudable que persigue la aplicación de ese Derecho tal cual es, es decir, como Derecho y con arreglo a los principios de interpretación del seno jurídico de donde procede. Es ilustrativo la sentencia del 4 de julio de 2006 del Tribunal Supremo de España, cuyos argumentos resumen los principios de esta tesis:

3. Argumento funcional: cuando el Derecho extranjero es aplicable al fondo del asunto opera como Derecho y no como hecho procesal. En dicho supuesto, el Derecho extranjero desarrolla la misma función que el Derecho nacional: resolver la controversia. Por lo tanto, la infracción de un Derecho extranjero supone un error jurídico que desnaturaliza el Derecho extranjero y que lleva a una solución antijurídica. Un error jurídico debe ser revisable, precisamente por tal carácter, en casación.

4. Argumento constitucional: si se permitiera la casación por infracción del Derecho nacional, pero no por infracción del Derecho extranjero aplicable, ello impediría el acceso a los recursos establecidos por la Ley. Y ello supondría una infracción de la tutela judicial efectiva y del derecho a un proceso equitativo. Además, colocaría en una situación de penosa e injustificada discriminación a los individuos cuyos derechos subjetivos quedan regulados, por voluntad del legislador, por un Derecho extranjero y no por el Derecho nacional. Se privaría a tales sujetos de esa solución justa.

5. Argumento conflictual. La incorrecta aplicación del Derecho extranjero puede justificar también un recurso de casación por infracción de la norma de conflicto nacional, es decir se violaría la norma indirecta nacional y afectaría la seguridad jurídica.

El Recurso de Casación es procedente cuando se niegue la aplicación de una norma extranjera, o se aplique indebidamente preceptos extranjeros, o se incurra en interpretación errónea de la ley extranjera adecuada para resolver la controversia.

En los países en que se admite el recurso de casación por la incorrecta aplicación del Derecho extranjero, además de España, son Bélgica, Italia, Suiza, Grecia, Turquía, Túnez y Francia. (CALVO CARAVACA \& 
CARRASCOSA GONZÁLEZ, 2007, p. 1857-1858). A nivel internacional la encontramos en los Tratados de Montevideo y en la CIDIP II los que se desarrollarán en el siguiente apartado.

6. Tesis intermedia: admite la casación ante la falta de aplicación del derecho extranjero y la niega cuando se aplica en forma incorrecta.

\section{LEGISLACIÓN ARGENTINA}

\section{Legislación Argentina de Fuente Interna}

\section{Código Civil y Comercial de la Nación Argentina}

El Código Civil y Comercial desarrolla esta temática en el artículo 2595 (Aplicación del derecho extranjero) de una extensión considerable. Cuenta con tres literales, en los que resuelve diferentes cuestiones relacionadas, a saber:

1. la aplicación e interpretación del derecho extranjero,

2. la covigencia o vigencia simultánea o sucesiva de Derechos en el Estado cuyo ordenamiento jurídico se declara aplicable y

3. la multiplicidad de Derechos aplicables a una o varias relaciones jurídicas. Este último, se refiere a la pluralidad metodológica y normativa.

A continuación, se explicará el literal a) el que, textualmente reza:

Artículo 2595.- Aplicación del derecho extranjero. Cuando un derecho extranjero resulta aplicable:

el juez establece su contenido, y está obligado a interpretarlo como lo harían los jueces del Estado al que ese derecho pertenece, sin perjuicio de que las partes puedan alegar y probar la existencia de la ley invocada. Si el contenido del derecho extranjero no puede ser establecido se aplica el derecho argentino ${ }^{15}$; (CÓDIGO CIVIL Y COMERCIAL DE LA NACIÓN ССyC, 2014, p. 446)

Para una correcta comprensión es necesario analizar la primera oración: "el juez establece su contenido." El problema radica en desentrañar el sentido de esta expresión, si se la interpreta en forma literal, conduciría a un ilógico ya que el juez argentino no fija el contenido del Derecho extranjero. El Derecho extranjero ya está establecido por decisión del legislador foráneo, lo que puede hacer el juez argentino es constatar, averiguar, verificar. Toda la doctrina interpreta esta frase en consonancia con la siguiente: "y está obligado", en el sentido que el juez argentino tiene la obligación de aplicar el Derecho extranjero, es decir, aunque no lo dice expresamente, se infiere que el tratamiento del Derecho extranjero es de oficio. (SOTO, 2016)

\footnotetext{
${ }^{15}$ Dicho artículo se puede consultar en: ARGENTINA. Códigos (2014) Código Civil y Comercial de la Nación. $1^{\circ}$ Edición. Ciudad Autónoma de Buenos Aires, Argentina: Infojus, 2014, p.446
} 
Continúa diciendo: "y está obligado a interpretarlo como lo harían los jueces del Estado al que ese derecho pertenece". Claramente se puede notar que adopta el postulado central de la Foreign Court Theory, formulado por la teoría del Uso Jurídico de Goldschmidt, explicada en el punto anterior. No hay ninguna duda, se apartó de la teoría de la Comitas Gentium sustentada en el anterior artículo 13 del Código de Vélez que en su nota citaba a Story, ampliamente criticada por toda la doctrina.

Entonces, el juez nacional debe valerse no sólo del texto y vigencia del Derecho extranjero sino también de su alcance y sentido vale decir, doctrina, jurisprudencia, usos, prácticas y costumbres del ordenamiento jurídico extranjero -al igual que como se procede con la interpretación de la ley nacional en forma coherente con el artículo 2 del Código- que equivale a tomar en consideración a todas las fuentes del Derecho en sentido objetivo.

En este aspecto se resaltan las enseñanzas de Goldschmidt en cuanto a que el juez argentino debe interpretar el Derecho extranjero con la mentalidad del juez extranjero y no con la mentalidad argentina, el Derecho Chino se interpreta con la mentalidad china y no argentina. Como afirmara la sentencia del juez inglés, al aplicar el Derecho Belga en cuanto a que se consideraba sentado en Bélgica, vale decir que se ubicaba en el país de origen, como sentado en los estrados extranjeros. Este artículo es otro claro ejemplo del diálogo de fuentespropuesto por el Profesor Jayme $(1995)^{16}$-ya que toma casi en forma literal ${ }^{17}$ el artículo 2 de la Convención Interamericana sobre Normas Generales de Derecho Internacional Privado de Montevideo de 1979 (CIDIP II) el que se desarrollará en el próximo apartado. Además, es acorde con la jurisprudencia argentina, por ejemplo, en el caso Soto, Javier c. EXXE S. $A^{18}$, la Corte de Justicia de la Provincia de Buenos Aires aplicó, en un contrato de trabajo con lugar de cumplimiento en Perú, el artículo 2 del Protocolo Adicional a los Tratados de Montevideo de 1889 y el 2 de la Convención Interamericana sobre Normas Generales de Derecho Internacional Privado de Montevideo de 1979, por el que no se requiere -reconoce la Suprema Corte- que el Derecho extranjero aplicable se alegue o pruebe por las partes.

En igual sentido, se expidió en los autos Banco de la Provincia de Buenos Aires c. Melendi, Omar Darío y

\footnotetext{
${ }^{16}$ Muchas veces el juez, al tener que resolver un caso con elementos extranjeros se encuentra con normas de fuente interna y normas de fuente internacional que reglamentan la misma situación, pero con soluciones diferentes, o sea no complementarias sino abiertamente contradictorias. Para aliviar estas inconsistencias el Profesor Erik Jayme (1995), propuso un método denominado diálogo de las fuentes. En síntesis y partiendo de la base que LA PLURALIDAD DE FUENTES DEL DERECHO INTERNACIONAL PRIVADO requiere de la coordinación de las leyes en el interior del sistema jurídico, el diálogo de fuentes consiste en la aplicación simultánea, coherente y coordinada de todas las fuentes legislativas, tanto internacional como interna convergentes, en la medida en que sean complementarias y coherentes, de modo de eliminar la norma incompatible solamente cuando se verifica que la contradicción que ella causa es insuperable. Véase JAYME, Erik. Identité culturelle et intégration: le droit international privé postmoderne. Cours général de droit international privé Recueil des cours, n²51, 1995, p.9-268

${ }^{17}$ Se afirma casi literal porque esta Convención no utiliza la palabra interpretar sino aplicar el derecho extranjero

${ }^{18}$ Dicha sentencia se puede consultar en: ARGENTINA. Suprema Corte de la Provincia de Buenos Aires-SCBA. Soto, Javier c. EXXE S.A. 28 de abril de 2004 LLBA, 2004, 18-1318.
} 
otra s/ cobro ejecutivo del $2014^{19}$.

Sin embargo, la aplicación de oficio de Derecho extranjero puede llegar a ser una tarea pesada sobre los jueces argentinos acostumbrados a aplicar el Derecho nacional. Tarea que consiste en averiguar, informarse, constatar un Derecho que muchas veces es esquivo, ajeno, extraño, por lo cual agrega el siguiente párrafo," sin perjuicio de que las partes puedan alegar y probar la existencia de la ley invocada". Pero hay que resaltar que las partes acompañan al juez en el proceso de informarse, interpretar y constatar el Derecho extranjero, pero si las partes nada dicen, la aplicación del Derecho extranjero sigue siendo obligación en cabeza del juez. (TONIOLLO, 2015)

Esta fórmula es similar a la dispuesta en los Protocolos Adicionales de los Tratados de Montevideo, en las Convenciones Interamericanas dictadas bajo el marco de las CIDIP y en los Acuerdos de MERCOSUR (FELDSTEIN DE CÁRDENAS, 1994, p.35), como se anotará en el próximo apartado.

Si bien el artículo no detalla los medios de prueba, la mayoría de los mismos y vías de información son los que fueron enumerados en el apartado anterior y han sido previstos por los Convenios vigentes que son bastante semejantes.

Finaliza con una frase muy cuestionada y de delicada interpretación. "Si el contenido del derecho extranjero no puede ser establecido se aplica el derecho argentino".

En primer lugar, surge la siguiente pregunta ¿qué quiso decir el legislador al afirmar que el Derecho extranjero no puede ser establecido? Se puede asumir que refiere a conocido, accedido, investigado, es decir, que no se puede llegar a él. En esta última frase el problema es más teórico que práctico ya que con el avance de las telecomunicaciones y las redes diplomáticas y consulares, virtualmente es posible establecer el contenido del Derecho extranjero, más aún cuando el juez tiene amplias facultades para investigar su existencia y contenido.

También se puede interpretar que se refiere a las lagunas del Derecho que, como todo Derecho, el extranjero puede presentar vacíos, ser insuficiente y podría ser que tampoco exista una jurisprudencia o doctrina que cubra los vacíos legales ya que este artículo remite a la totalidad del Derecho extranjero, incluidos doctrina, jurisprudencia y usos y costumbres jurídicas. Sin embargo, es una interpretación muy forzada ya que no surge de esta última frase.

Esta frase no es clara y es criticada por la doctrina ya que si se aplica más de lo debido puede llevar al juez a no investigar el Derecho extranjero, aun cuando fuere posible hacerlo, dándole la posibilidad de aplicar su propio Derecho que es el más conoce. La idea es que esta frase no debe ser interpretada como que, en un caso concreto y ante la primera dificultad el juez deje de lado la legislación extranjera y aplique el propio, como un incentivo a

\footnotetext{
${ }^{19}$ Para mayor información, véase: ARGENTINA. Suprema Corte de la Provincia de Buenos Aires-SCBA. Banco de la Provincia de Buenos Aires c. Melendi, Omar Darío y otra s/ cobro ejecutivo. 17 de diciembre de 2014. Recuperado el 5 de febrero de 2017, de: http://fallos.diprargentina.com/2015/06/banco-de-la-provincia-de-buenos-aires-c.html
} 
aplicar el nacional que es el conocido. Sumado a esto, en Argentina no existe un fuero específico de Derecho Internacional Privado, por lo que, los jueces que están acostumbrados a aplicar todos los días el Derecho Argentino, ya sea civil, comercial, penal, se les presenta en un determinado momento una controversia internacional y deben adquirir los conocimientos de un Derecho que muchas veces es totalmente diferente al que suelen aplicar. No obstante, en Derecho Internacional Privado, siempre se mantiene la obligación de aplicar de oficio el Derecho extranjero, o sea se deben agotar todas las vías de alcance antes de aplicar Derecho Argentino y únicamente en casos excepcionales en los que sea difícil establecer la existencia y contenido del extranjero se aplica el propio.

Ahora bien, al ser una salida extrema, el juez debe seguir el procedimiento de aplicar el Derecho extranjero de oficio, es decir, en forma obligatoria. Por lo tanto, cuando no acceda al mismo, debe fundar razonablemente su decisión y justificar la imposibilidad de establecer la legislación extranjera, obligación que le recae también por el artículo 3 (deber de resolver) del mismo Código. Dicho artículo obliga a los jueces y se aplica extensivamente a todos aquellos que deban decidir sobre una controversia jurídica, léase los árbitros, a resolver los asuntos sometidos a su jurisdicción mediante una decisión razonablemente fundada, es decir no pueden amparase en la insuficiencia del Derecho. Se entiende que este deber de fundar razonablemente las sentencias se vincula con las fuentes del Derecho y con los usos, buenas prácticas y costumbres jurídicas, la jurisprudencia, las decisiones de los tribunales internacionales en los supuestos previstos por la Constitución y las fuentes de conocimiento, es decir, la doctrina. (LORENZETTI, 2014, p.39-41)

En lugar de establecer esta regla de cierre de acudir directamente al Derecho Argentino, la mayoría de la doctrina internacionalista, entre ellos, Fernández Arroyo (2014), All (2014) Albornoz (2014) ${ }^{20}$ opinan que hubiese sido preferible acudir a un criterio flexible, es decir al del ordenamiento que presenta vínculos más estrechos que, en algunos casos, es fácilmente identificable. (MEDINA et al, 2014, p. 782)

\section{CONTROL DE CONSTITUCIONALIDAD}

Antes de continuar con el análisis del literal b) se dedicarán unas líneas a una problemática que se plantea en base a la aplicación del Derecho extranjero de modo que el juez argentino debe fallar como lo haría el juez del país cuyo Derecho resulta aplicable, consistente en admitir o no la posibilidad del control de constitucionalidad del Derecho extranjero. Como observa el Profesor Boggiano (op. cit., p.238) la imitación de la probable sentencia del juez extranjero requiere tomar en cuenta todas las disposiciones que él tomaría. Así el juez argentino deberá considerar la constitucionalidad de una norma extranjera según lo haría el juez foráneo. Para aclarar al lector, el 
tema que se plantea no es la constitucionalidad del Derecho extranjero en base a la Constitución Argentina, tema que corresponde a Orden Público Internacional, sino la constitucionalidad del mismo referida a la propia constitución del Estado cuya legislación fue declarada aplicable por la norma de conflicto. Así, el Profesor Goldschmidt, cuando se debatía la aprobación del artículo 2 de la Convención Interamericana de Normas Generales de Derecho Internacional Privado, puso énfasis en la tolerancia que debe regir entre los Estados que forman parte de la comunidad internacional y esa tolerancia exige que, si se aplica el Derecho extranjero, no se le tergiverse ni se le distorsione. (FERMÉ, 1987)

Henríquez Maionica $(2006,219-221)$ al comentar la Ley de Derecho Internacional Privado venezolana considera que, si el Derecho extranjero declarado aplicable por la regla de conflicto establece la posibilidad al juez para controlar la constitucionalidad del Derecho, éste deberá hacerlo, ya que deriva del principio iura novit curia, y, por ende, de su aplicación de oficio. Y también plantea la situación inversa, es decir la posibilidad de que un juez extranjero controle la constitucionalidad del Derecho nacional y lo resuelve diciendo que, si el Tribunal extranjero observa contraste entre la Constitución y una norma de cualquier rango que fuere, no se aplicará la norma en cuestión, en beneficio de la aplicación de la disposición constitucional.

En contra de esta postura, Batiffol \& Lagarde (1995) indican que el control de la constitucionalidad es, al menos en Francia, una actividad política que le corresponde sólo al Consejo Constitucional, por lo que un juez francés no puede presumir tenerla, porque en su país, carece de tal competencia. En consecuencia, al juez no se le permite controlar la constitucionalidad.

Fernández Rozas (1995, p.1004-1013), siguiendo a Siehr, sistematiza cuatro variantes en las cuales se puede producir el control de constitucionalidad del Derecho extranjero:

1. Que un Tribunal o un órgano político del Estado extranjero cuyo Derecho reclama la norma de conflicto del foro haya afirmado con eficacia erga omnes la legitimidad constitucional de la norma.

2. Que ese Tribunal o, en su caso, órgano político, haya afirmado con eficacia erga omnes la ilegitimidad constitucional de la norma.

3. Que el procedimiento de control constitucional del Derecho reclamado por la norma del conflicto del foro esté pendiente de solución.

4. Que el Tribunal o, en su caso, el órgano político, del Estado extranjero no se haya pronunciado sobre la constitucionalidad de la norma reclamada.

En relación con los dos primeros supuestos, el Juez del foro debe resolver de acuerdo con los criterios expresados por el Tribunal u órgano político extranjero. Dicha asunción deriva del propio mandato contenido en

\footnotetext{
${ }^{20}$ La opinión de los mencionados autores se puede consultar en: MEDINA, Graciela; RIVERA, Julio (dir.) ESPER, Mariano (coord.) Código Civil y Comercial de la Nación. Tomo VI. Comentario de ALL, Paula; ALBORNOZ, Jorge. Buenos Aires, Argentina: La Ley, 2014, 1026 p.
} 
la norma de conflicto de aplicar el Derecho extranjero en su propio contexto, tal y como lo harían las autoridades del país en cuestión. Naturalmente, la aplicación de la norma extranjera declarada constitucional encontrará siempre el límite de no ser contraria al orden público del foro.

En el tercer supuesto cabe la posibilidad de suspender el proceso en el foro siempre que sea relevante para el Juez del foro. Dicha relevancia requiere, claro está, que exista un procedimiento abierto en el extranjero acerca de la constitucionalidad de dicha norma ante el órgano constitucional competente para ello; y que el cambio de la norma impugnada obligue a todos los órganos que deban aplicarla y, por ende, al juez del foro.

La cuarta y última situación si en el sistema constitucional extranjero se entiende que la norma impugnada es válida hasta que no exista un pronunciamiento expreso por parte del órgano constitucional, dicha norma sigue produciendo toda su eficacia jurídica y vincula al juez del foro, es decir tiene la obligación de aplicarla.

En Argentina, la Profesora Feldstein de Cárdenas (2008, p.50-54) opina que los tribunales judicialesnacionales o extranjeros, especializados o no-, carecen de competencia para declarar la inconstitucionalidad de la ley extranjera en base a la Constitución extranjera, por cuanto su misión consiste en interpretar las leyes o preceptos de leyes extranjeras que no afecten la propia Constitución.

Es de lamentar que el legislador ${ }^{21}$ no haya aclarado el tema y se haya desperdiciado esta oportunidad, por lo tanto, habrá que esperar a la jurisprudencia para visualizar alguna tendencia al respecto.

\section{SISTEMAS JURIDICOS COVIGENTES}

Retomando el análisis del artículo, el literal b. expresamente dispone:

b. si existen varios sistemas jurídicos covigentes con competencia territorial o personal, o se suceden diferentes ordenamientos legales, el derecho aplicable se determina por las reglas en vigor dentro del Estado al que ese derecho pertenece y, en defecto de tales reglas, por el sistema jurídico en disputa que presente los vínculos más estrechos con la relación jurídica de que se trate; (CÓDIGO CIVIL Y COMERCIAL DE LA NACIÓN -CCyC, 2014, p. 446)

En este apartado se plantean diversos supuestos de covigencia, es decir vigencia simultánea y sucesiva de las leyes.

Los casos de vigencia simultánea se producen en los Estados plurilegislativos donde coexisten diversos ordenamientos jurídicos de Derecho Privado ya sea en el ámbito territorial, por ejemplo, como los Estados Unidos, Canadá y en regiones autónomas de España o Escocia, los cantones en Suiza y en Polonia. También puede ser la vigencia simultánea de Derechos en el ámbito personal, por ejemplo, en Nigeria, Indonesia, Israel y otros Estados de África o de Asia, donde el Derecho tiene en consideración cuestiones étnicas o religiosas. Los de

\footnotetext{
${ }^{21}$ La alocución "legislador" es usada en sentido amplio, incluyendo a la Comisión de más de cien profesores que preparó el Proyecto del Código, presidida por los profesores y magistrados Ricardo L. Lorenzetti, Elena Highton de Nolasco y Aída Kemelmajer de Carlucci
} 
vigencia sucesiva aluden a una modificación o reforma de la legislación en el tiempo. En ambos casos, la directiva es que el Derecho aplicable lo determinen las reglas en vigor dentro del Estado al que ese Derecho pertenece, adoptando la teoría de la remisión interna. Esto significa que, en los casos de vigencia simultánea, si hay un Derecho Federal o Derecho interregional central o normas distribuidoras, será ese el que resuelva el problema y en los de vigencia sucesiva la solución hay que buscarla en el Derecho transitorio extranjero, que mandan aplicar el anterior o el nuevo Derecho. (HERRERA, et al, 2015, p. 317,318)

La teoría de la remisión interna adoptada en esta parte del articulado para la solución de los problemas del ámbito territorial y espacial del Derecho extranjero, está en sintonía con la teoría del uso jurídico, ya que, el juez argentino deberá indagar cómo procedería un juez del Estado correspondiente, según los mecanismos que prevea su propio ordenamiento para resolver los problemas de covigencia.

En caso de ausencia de disposiciones del Derecho extranjero aplicable y como punto de conexión subsidiario, se aplica el Derecho en disputa que presente los vínculos más estrechos con la relación jurídica de que se trate. Por ejemplo, si el punto de conexión en la regla de conflicto es el domicilio y la persona se encuentra domiciliada en el Estado de Nueva York, no hay duda que el juez argentino aplicará la ley del Estado de Nueva York y no la ley del Estado de California. La solución no sería tan clara si el punto de conexión fuese la nacionalidad. Puntualmente, en Estados Unidos cobra un papel protagónico la jurisprudencia como fuente de Derecho Internacional Privado estatal y la inexistencia de un Derecho Internacional Privado federal ya que los Restatements no son obligatorios. Entonces, el juez tendrá que examinar en cada caso los vínculos y grado de proximidad que se aprecien, para tomar decisiones equitativas, adoptando un criterio más flexible conforme lo dispuesto en el artículo 2597 (Cláusula de excepción) también denominada cláusula escapatoria ya establecida en forma doctrinaria, por ejemplo, por Batiffol (1981) y en algunas legislaciones como Suiza, Macedonia, Bélgica y la Unión Europea. (SOTO, op. cit.)

\section{CÓDIGO PROCESAL CIVIL Y COMERCIAL DE LA NACIÓN ARGENTINA}

El artículo 377 (Carga de la Prueba) establece la carga de la prueba en cabeza de la parte que afirme la existencia de un precepto jurídico que el juez no tenga el deber de conocer. Sin embargo, en el caso que la ley extranjera invocada por alguna de las partes no hubiere sido probada, el juez podrá investigar su existencia, y aplicarla al litigio, facultando al juez a aplicarla de oficio. De la redacción de la norma se infiere que ha adoptado la teoría intermedia. En efecto, con la reforma efectuada por la Ley $N^{\circ} 22.434$, se añade a dicho precepto un tercer párrafo que, si bien continúa colocando como carga de las partes alegar el Derecho extranjero, concede al juez argentino la potestad de aplicarlo de oficio. 


\section{LEGISLACIÓN ARGENTINA DE FUENTE INTERNACIONAL O CONVENCIONAL}

\section{Protocolos Adicionales a los Tratados de Montevideo de 1889 y de 1940}

Los artículos 2 de los Protocolos Adicionales a los Tratados de Montevideo de 1889 y de 1940 establecen que el Derecho de un Estado Parte debe ser aplicado de oficio, lo que significa que es Derecho en los demás Estados Partes- siguiendo la filosofía de Federico Carlos de Savigny- aun cuando las partes no lo prueben, sin perjuicio que ellas puedan alegar y probar la existencia y contenido de la ley.

En los artículos 5 y 6 tratan de la información del Derecho extranjero y obligan a los gobiernos a intercambiarse recíprocamente dos ejemplares auténticos de las leyes vigentes y de las que posteriormente se sancionen en sus Estados.

Conforme los artículos 3 de ambos Protocolos, todos los recursos acordados por la ley procesal del lugar del juicio para los casos resueltos según su propia legislación, serán igualmente admitidos para los que se decidan aplicando las leyes extranjeras de los Estados partes, es decir admiten el recurso de casación. (FELDSTEIN DE CÁRDENAS, op. cit.,1994, p.36)

\section{Conferencia Especializada Interamericana de Derecho Internacional Privado - CIDIP II- Montevideo 1979}

\section{Convención Interamericana sobre Normas de Derecho Internacional Privado}

El artículo 2 recepta la teoría del uso jurídico de Goldschmidt y, como ya se mencionó, esta Convención fue fuente del nuevo Código Civil y Comercial de la Nación, por lo tanto, es similar a lo desarrollado anteriormente.

Textualmente dice:

Los jueces y autoridades de los Estados parte estarán obligados a aplicar el derecho extranjero tal como lo harín los jueces del Estado cuyo derecho resultare aplicable, sin perjuicio de que las partes puedan alegar y probar la existencia y contenido de la ley extranjera invocada (CONVENCIÓN INTERAMERICANA SOBRE NORMAS DE DERECHO INTERNACIONAL PRIVADO, 1979, ART. 2)

En el artículo 4 adopta el principio de no discriminación procesal entre el nacional y el extranjero, admitiendo todos los recursos procesales en términos similares que los Protocolos Adicionales a los Tratados de Montevideo de 1889 y de 1940. 


\section{$\underline{\text { Convención Interamericana sobre Pruebas e Información del Derecho Extranjero }} \underline{22}$}

En los artículos 2 y 3 dispone la cooperación internacional en la materia del Derecho extranjero, obligando a las autoridades de cada uno de los Estados parte a proporcionar los elementos probatorios o informes sobre el texto, vigencia, sentido y alcance legal de su derecho.

Serán considerados medios idóneos, entre otros, los siguientes:

1. La prueba documental, comprendiendo copias certificadas de textos legales con indicación de su vigencia, o precedentes judiciales;

2. La prueba pericial, consistente en dictámenes de abogados o expertos en la materia;

3. Los informes del Estado requerido sobre el texto, vigencia, sentido y alcance legal de su derecho sobre determinados aspectos.

\section{Convenio Argentino-Uruguayo sobre Aplicación e Información del Derecho Extranjero de}

De igual manera que la Convención sobre Normas de Derecho Internacional Privado de 1979, en el artículo 1, considera que el Derecho extranjero es un hecho notorio y el tratamiento procesal es de oficio.

Los informes se efectuarán a través de los Ministerios de Justicia quienes están obligados a responder a la brevedad sobre los siguientes aspectos que se le soliciten:

1. legislación vigente aplicable;

2. reseña de los fallos de los tribunales de justicia o de órganos administrativos

3. usos y costumbres del lugar, cuando constituyan fuente de derecho;

4. reseña de la doctrina nacional.

En el artículo 2 admite todos los recursos procesales

\section{Mercado Común del Sur - MERCOSUR $\underline{23}$}

Protocolo de Las Leñas de Cooperación y Asistencia Jurisdiccional en Materia Civil, Comercial, Laboral y

\footnotetext{
22 Vigente en los siguientes países: Argentina, Brasil, Chile, Colombia, Ecuador, España, Guatemala, México, Paraguay, Perú Uruguay y Venezuela

${ }^{23}$ El MERCOSUR fue creado por el Tratado de Asunción de 1991 entre Argentina, Brasil, Uruguay y Paraguay, al cual en fases posteriores se han incorporado Venezuela y Bolivia, ésta última en proceso de adhesión. Es un proceso de integración regional con el objeto de logar la libre circulación de bienes, servicios y factores productivos, el establecimiento de un arancel externo común y de una política comercial común respecto a terceros Estados, la coordinación de políticas macroeconómicas y sectoriales y el compromiso de armonizar sus legislaciones, objetivo no alcanzado. Básicamente, la estructura institucional del MERCOSUR está organizada por el Protocolo Adicional al Tratado de Asunción sobre la Estructura Institucional del Mercosur de 1994-Protocolo de Ouro Preto de 1994-.
} 


\section{Administrativa de 1992 con la reforma de $2002 \underline{24}$}

En los artículos 28 y 29 obliga a las Autoridades Centrales de los Estados Partes a suministrar informes en materia civil, comercial, laboral, administrativa y de Derecho Internacional Privado. Tal información podrá también efectuarse a través de informes diplomáticos o consulares del Estado Parte de cuyo derecho se trate.

Acuerdo de Cooperación y Asistencia Jurisdiccional en Materia Civil, Comercial, Laboral y Administrativa entre los Estados Partes del MERCOSUR y la República de Bolivia y la República de Chile del 2002.

Establece la igualdad de trato procesal y los Estados Partes se comprometen a designar una Autoridad Central encargada de recibir y tramitar pedidos de asistencia jurisdiccional en materia civil, comercial, laboral y administrativa y a enviar a las autoridades jurisdiccionales del otro Estado Parte, los exhortos en materia civil, comercial, laboral o administrativa, cuando tengan por objeto diligencias de mero trámite, tales como citaciones, intimaciones o apercibimientos, emplazamientos, notificaciones u otras semejantes y recepción u obtención de pruebas.

\section{CLÁUSULA DE EXCEPCIÓN}

En el artículo 2597 (Cláusula de excepción) establece una vía escapatoria que es toda una novedad en el Derecho Argentino, ya que el anterior Código no contenía ningún artículo similar. Es una técnica reconocida en el derecho comparado cuando se trabaja en la armonización de los diferentes sistemas. Los casos multinacionales son complejos y muchas veces son rebeldes a una solución rígida. La norma indirecta utiliza puntos de conexión rígidos-domicilio, residencia, situación de los bienes-. Sin embargo, en la actualidad hay una cierta tendencia a la flexibilización, porque se van incorporando puntos de conexión flexibles basados en conceptos jurídicos indeterminados, que le otorgan al juez un margen de discrecionalidad y una cierta libertad de apreciación sobre la concreción del punto de conexión, como es el caso del mencionado artículo. Los jueces pueden marginar el derecho que declara aplicable la norma de conflicto cuando el caso carece de relación con ese derecho. Se abre paso, con carácter general, a un abandono de las conexiones rígidas que caracterizan al Derecho Internacional Privado Argentino con un considerable aumento de la discrecionalidad judicial. (MENICOCCI, 2014, 200, 201) Textualmente reza:

artículo 2597.- Cláusula de excepción. Excepcionalmente, el derecho designado por una norma de conflicto no debe ser aplicado cuando, en razón del conjunto de las circunstancias de hecho del caso, resulta manifiesto que la situación tiene lazos poco relevantes con ese

\footnotetext{
${ }^{24}$ Vigente en los cuatro Estados Parte: Argentina, Brasil, Paraguay y Uruguay.
} 
derecho y, en cambio, presenta vínculos muy estrechos con el derecho de otro Estado, cuya aplicación resulta previsible y bajo cuyas reglas la relación se ha establecido válidamente. Esta disposición no es aplicable cuando las partes han elegido el derecho para el caso. (CÓDIGO CIVIL Y COMERCIAL DE LA NACIÓN, 2014, p.447)

En primer lugar, se resalta que es una excepción a la regla general y como tal, es de interpretación restringida sujeta, a determinadas condiciones y presenta ciertas limitaciones.

El funcionamiento es el siguiente: frente a una controversia, el juez competente argentino debe consultar, en primer lugar, si existe un Tratado Internacional aplicable al caso, en su defecto al Derecho Interno Argentino y, siempre que el caso objeto de litigio no se resuelva por la aplicación de una norma directa, sino que, a través de la norma indirecta, se remita al derecho aplicable que, en definitiva, solucionará el caso. Sin embargo, esa norma de conflicto puede conducir a un derecho que tiene vínculos poco relevantes con el caso y se ha tornado abstracta, injusta o discordante con la vida real. Pero, simultáneamente, el magistrado encuentra otro derecho con el cual se encuentra estrechamente conectado. Entonces, por vía de excepción, la norma le otorga la posibilidad al juez, que en definitiva es el que va a decidir, dejar de lado el derecho normalmente competente, seleccionado por la norma indirecta y resolver la controversia aplicando ese derecho que presenta vínculos más estrechos con el caso. Generalmente se aplica en los casos de responsabilidad civil por hechos ilícitos, contaminación transfronteriza y responsabilidad del fabricante. (SOTO, op.cit.)

Para una mejor comprensión del tema, a continuación, se relatará el leading case, es decir, el caso que dio origen a este criterio flexible y fue resuelto por la Corte del Estado de Nueva York, en los autos caratulados Babcock vs. Jackson de 1963. Se trató de un reclamo de compensación económica por responsabilidad civil por un hecho ilícito (en idioma original torts). En septiembre de 1960, el matrimonio Jackson, en compañía de la Sra. Georgia Babcock, todos residentes en Rochester, salieron desde esa ciudad con destino a Canadá en un paseo de fin de semana. La Sra. Babcock había sido invitada por los Jackson y el viaje se realizó en automóvil de propiedad de William Jackson. Pasaron a Canadá y en la carretera perdió el control del auto cuando estaba atravesando la provincia canadiense de Ontario. La Sra. Babcock resultó seriamente herida y luego de su regreso al Estado de Nueva York demandó al Sr. Jackson. La demandante no alegó ninguna ley, lo que hizo presumir que ella suponía que se aplicaba la ley del Estado de New York. Por su parte, el demandado adujo que la ley aplicable era la ley del lugar donde ocurrió el accidente, o sea Canadá, por lo tanto, no era responsable ya que, según esa ley el conductor de un vehículo que no hubiese sido utilizado para transporte de pasajeros no era responsable por las heridas corporales o muerte de cualquiera de las personas que se encontrasen en el automóvil. El juez competente era el del Estado de Nueva York y la ley aplicable era la de Canadá ya que el First Restatement of Conflict of Laws receptaba la teoría de la incorporación legislativa de los derechos subjetivos anteriormente analizada- conforme la cual los derechos sustantivos y las responsabilidades extracontractuales se regían por la ley del lugar del hecho que las originaban. Sin embargo, la sentencia se apartó de la ley competente, del criterio rígido, y tuvo en cuenta the 
center of gravity- centro de gravedad- o grouping of contacts-agrupacion de conexiones y formula la regla de la ley más íntimamente relacionada con el objeto del litigo. Como fundamento para la adopción de esta nueva regla flexible y apartarse del criterio rígido realizó una comparación entre los intereses y las diferentes conexiones del Estado de New York y las de Ontario, dejando en claro que es el Estado de Nueva York el que incuestionablemente tenía un interés directo porque tanto el damnificado como el demandado residían en Nueva York, la licencia y el seguro del automóvil también se otorgaron en ese Estado, tanto el punto de partida del viaje como el del destino era Nueva York. La única relación con Ontario era que el accidente ocurrió allí, por lo tanto, existía una acumulación de contactos en el Estado de Nueva York. En consecuencia, la ley que presentaba vínculos más estrechos era la del foro y resolvió ordenar la compensación en base su ley, es decir, a la ley del Estado de Nueva York ${ }^{25}$ (DOS SANTOS, 1990, 248-250).

Además de este fundamento, se basó en otro principio no receptado por el legislador argentino y era el interés del Estado. Justamente, en este caso la finalidad de la disposición canadiense era prevenir demandas fraudulentas contra las compañías de seguros por confabulación entre los pasajeros y conductores, protegía a las compañías de seguro de Ontario y no del Estado de New York.

De allí, ha tenido una gran repercusión mundial, como lo demuestra la Convención de La Haya de 1971 sobre ley aplicable a los accidentes de circulación por carretera y, en nuestro ámbito, el Protocolo mercosureño de San Luis sobre accidentes de tránsito ${ }^{26}$. En la Ley suiza de Derecho Internacional Privado de 1987 y en el Código de Derecho Internacional Privado de Bélgica de 2004, la flexibilidad tiene alcance general, ya que los artículos 15de la Ley Suiza y 19- Código de Bélgica- respectivamente consagran la llamada cláusula de excepción sin limitación material. (FRESNEDO DE AGUIRRE, op. cit., p.271)

La aplicación de estos criterios flexibles (a partir de la "revolución (norte) americana") también ha merecido críticas ya que estos enfoques contemporáneos sacrifican los objetivos tradicionales de esta rama del Derecho, tales como la certeza, la uniformidad, previsibilidad y la cohesión e integración internacional. Los abogados no pueden dar consejos definitivos a sus clientes; la incertidumbre y la inseguridad jurídica alientan los litigios, fomenta apelaciones y disminuye la posibilidad de arreglos amistosos entre las partes. Resulta más costosos y prolongados los métodos flexibles que la vieja regla rígida. (FRESNEDO DE AGUIRRE, 2003b, p. $1173,1174)$

Relacionando el leading case norteamericano con la reforma del Código Civil y Comercial, por primera vez, el Derecho Argentino cuenta con una flexibilización expresa. En efecto, el legislador argentino, en plena

\footnotetext{
${ }^{25}$ A partir de esta sentencia comienza la denominada revolución judicial y con los aportes doctrinarios de Cavers, Currie y Ehrenzweig se plantea una reformulación del First Restatement que culmina con el Restatement Second on the Conflict of Laws

${ }^{26}$ El Protocolo de San Luis en materia de responsabilidad civil emergente de accidentes de tránsito entre los Estados parte del MERCOSUR fue aprobado por Dec. N 1/96 del CMC
} 
conciencia de la atipicidad de los casos, ha flexibilizado la elección rígida al adoptar, en el artículo comentado, la cláusula general de excepción y las especiales, en materia de responsabilidad parental (artículo 2639) y contractual (artículo 2653). Las mencionadas cláusulas permiten escaparse de la elección operada por el legislador en abstracto, cuando se reúnan los requisitos por ellas exigidos y aplicar otro derecho más conectado, más justo, más protector del derecho humano, como el interés superior del niño del artículo 2639. (RABINO, 2016, p.11)

Todos los razonamientos y las teorías utilizadas para resolver los problemas de la norma de conflicto no son neutros, sino que tienen en vistas la solución material. En esa inteligencia es que la Comisión Redactora, en los Fundamentos del Anteproyecto del Código Civil y Comercial señaló que, dada la complejidad intrínseca de las controversias vinculadas a más de un derecho, se prefirieron soluciones a la vez sencillas y de cierta flexibilidad, a fin de favorecer el equilibrio entre la certeza y la necesidad de adaptación a las particularidades del caso. Específicamente, en materia de responsabilidad civil por hechos ilícitos, se admite también que, si del conjunto de circunstancias del caso se desprende que el hecho dañoso presenta vínculos manifiestamente más estrechos con otro país distinto del indicado por la norma, se aplique el derecho de ese otro país. (LORENZETTI et al, 2012, p.288, 298)

En el derecho argentino se incluyen, primordialmente, problemas de daños a personas o a sus bienes no contractuales referidos a accidentes de tránsito; daños derivados de productos; a la intimidad; propia imagen; al honor; al nombre. En los daños al ambiente se contempla la contaminación del mar por hidrocarburos; nucleares; uso de plaguicidas; contaminación de ríos y aguas en general; afectación a la fauna y flora, entre otros. Igualmente pueden presentarse problemas de responsabilidad civil por daños derivados de productos. La rigidez de la regla del lugar en donde se produce el daño ha llevado a la formulación de correctores ya que el derecho aplicable puede resultar insuficiente para resarcir la lesión. Ese es el caso de la relación obligacional constituida en el extranjero, cuyo producto allí fue fabricado y trasladado al país para su uso o implante El defecto o vicio del producto no fue advertido por la apariencia de buena calidad y la víctima no advirtió su defectuoso funcionamiento. En ese caso, el damnificado tiene derecho a que se aplique el régimen jurídico que le brinde mayor extensión en la reparación al daño experimentado y en tal sentido, la regla del lugar donde se experimenta el daño debe ceder por la ley del lugar de fabricación. Otro ejemplo, se advierte en el régimen patrimonial del matrimonio, que se rige por el primer domicilio conyugal, pero puede presentarse el supuesto que los cónyuges convivieron en un Estado el primer año y todo el resto del tiempo de duración de su matrimonio en un país que establece la separación de patrimonios. No sería razonable someterlos a una ley que, con el curso de los años, no presenta vínculos reales con los cónyuges (Herrera et al, op.cit., p.320)

Volviendo al artículo, para aplicar esta regla de los vínculos más estrecho se debe dar una serie de condiciones ya que la localización no es solo por proximidad geográfica: 
1. Que el derecho declarado aplicable por la regla de conflicto tenga vínculos poco relevantes con el caso.

2. Que exista una acumulación de contactos en otra dirección, es decir que se encuentre estrechamente conectado con otro derecho.

3. Que ese derecho sea previsible, por una cuestión de seguridad jurídica.

4. Que la relación jurídica haya nacido válida para ese derecho, porque de lo contrario, aplicaría el derecho más permisivo y

5. Que las partes no hayan elegido el derecho aplicable para el caso, en otras palabras, esta regla no se aplica en los casos en que se ejerce la autonomía de la voluntad. (SCOTTI \& BRODSKY, 2015, p.19, 20)

En materia de contratos y relacionándolo con el tema, el artículo 2653 (Cláusula de excepción) textualmente reza:

Excepcionalmente, a pedido de parte, y tomando en cuenta todos los elementos objetivos y subjetivos que se desprendan del contrato, el juez está facultado para disponer la aplicación del derecho del Estado con el cual la relación jurídica presente los vínculos más estrechos. Esta disposición no es aplicable cuando las partes han elegido el derecho para el caso. (CÓDIGO CIVIL Y COMERCIAL DE LA NACIÓN, 2014, p.458)

Las condiciones para que el juez pueda aplicar esta excepción son:

1. A pedido de cualquiera de las partes

2. No ejercicio de la autonomía de la voluntad

De la comparación de ambos artículos, se advierte que son similares, pero en materia de contratos es a pedido de parte, requisito que, en el artículo 2597, omite mencionar si la excepción funciona a pedido de parte o puede el tribunal, de oficio, instalar el caso de un derecho diferente al previsto. Y dice está facultado, es decir faculta al juez, en cambio la cláusula de excepción en las demás materias dice debe, en consecuencia, es obligatoria. (SOTO, op. cit.)

El Reglamento de Roma sobre la Ley Aplicable a las Obligaciones Contractuales (Roma I) del 2008 en su artículo $4^{\circ}$, adopta esta solución y establece una serie de presunciones-general y especiales- que ayudan a determinarlo, dejando al juez un amplio margen de apreciación, aunque no es exclusivo arbitrio del mismo. ${ }^{27}$

En el mismo sentido, no se puede dejar de advertir que esta solución debe ser tomada como excepción y que no sirva como cláusula de escape al juez para no aplicar Derecho extranjero y ante el primer inconveniente aplicar su ley que es en definitiva la que más conoce. En realidad, otorga tanto poder discrecional al juzgador que crea cierta incertidumbre ante la imposibilidad de predecir la posible sentencia, afectando la seguridad jurídica.

Finalmente, el Profesor Toniollo (2015) considera que la regla del artículo 2597 encapsula la teoría de los derechos adquiridos que recepta, de manera general, la Convención Interamericana sobre Normas Generales

\footnotetext{
${ }^{27}$ Para mayor información sobre el tema se puede consultar en PORCELLI, Adriana. Regulación jurídica de los contratos internacionales en el Código Civil y Comercial de la Nación Revista Electrónica del Instituto de Investigaciones "Ambrosio L. Gioja" Año IX, n² 15, 2015, p.79-121
} 
del Derecho Internacional Privado-CIDIP II- afirmando que se reconocerán en otros Estados aquellas relaciones jurídicas válidamente creadas en un Estado, salvo que sean contrarias al orden público.

Textualmente, el artículo 7 dispone:

Las situaciones jurídicas válidamente creadas en un Estado Parte de acuerdo con todas las leyes con las cuales tengan una conexión al momento de su creación, serán reconocidas en los demás Estados parte, siempre que no sean contrarias a los de su orden público. (CONVENCIÓN INTERAMERICANA SOBRE NORMAS DE DERECHO INTERNACIONAL PRIVADO, 1979, ART.7)

La doctrina internacionalista española, entre ellos Aguilar Navarro, consideran importante recurrir a los derechos adquiridos porque se humaniza el Derecho Internacional Privado (MIAJA DE LA MUELA, 1974, p. 21 23) y en definitiva este artículo promueve el diálogo de fuentes y sugiere brindar una coherencia al sistema en los casos de tal complejidad que necesitan una interpretación con principios del Derecho Constitucional e Internacional de Derechos Humanos.

En igual sentido, Profesor Erik Jayme (1995), afirma que los derechos humanos han cobrado un rol relevante a la hora de resolver los conflictos de leyes, propios del Derecho Internacional Privado. Su garantía y protección orientan a toda solución que se busque para un caso de Derecho Privado con elementos extranjeros, ya sea a nivel legislativo- nacional o internacional-, como a nivel jurisprudencial.

\section{CONCLUSIÓN}

El Código Civil y Comercial de la Nación constituye un cuerpo normativo pluricultural que recepta la realidad actual de Argentina. Por un lado, un país Latinoamericano, abierto a todas las personas del mundo, plasmado en el Preámbulo y en el artículo 20 de la Constitución Nacional (que garantiza a los extranjeros el goce de todos los derechos civiles), como factor de integración del conjunto de los microsistemas del Derecho Privado que no existen en el aislamiento, en el vacío, sin interrelación alguna. Y por el otro, un país inserto en un contexto mundial de integración, globalización y de negocios internacionales entre diferentes países con diversas culturas y modalidades de comercialización, en un mundo hiperconectado, con predominio de las tecnologías de la información y comunicación, TICs, que producen un intercambio frecuente, simultáneo y ubicuo entre las regiones más alejadas del planeta.

Además, sistematiza el Derecho Internacional Privado Argentino haciéndolo mucho más visible para todos los operadores jurídicos del país y del extranjero, codifica la extensa tradición doctrinaria y jurisprudencial argentina en esta materia y se esfuerza por compatibilizar las soluciones adoptadas en las convenciones internacionales en vigor en Argentina.

Puntualmente en el tema objeto del presente trabajo, se resalta su adecuada resolución, la finalización de los debates doctrinarios y jurisprudenciales que ocasionó el anterior artículo 13 del Código de Vélez, la recepción 
de la doctrina y jurisprudencia predominante y la concordancia con la reglamentación de la normativa de fuente convencional o internacional.

Es de destacar la aplicación de oficio del derecho extranjero, modificando la anterior regulación, imponiendo al juez argentino a interpretarlo "como lo harían los jueces del Estado al que ese derecho pertenece", por lo cual remite no solo al texto de la ley sino a los usos y costumbres, a la doctrina y a la jurisprudencia.

También es acertada la omisión, en su articulado, de los medios de prueba del Derecho extranjero, frente a los avances tecnológicos no es conveniente circunscribirse a un catálogo predeterminado de modos de prueba ya que en un futuro pueden descubrirse novedades hoy impensadas.

Sin embargo, no está exenta de críticas, fundamentalmente la última parte del inciso a. de artículo 2595 que deja una puerta abierta o una excusa para que el juez argentino, ante la primera dificultad, no investigue el Derecho extranjero y aplique el propio que es el que más conoce.

De la misma manera, incorpora, en el artículo 2597, la cláusula de excepción o también llamada escapatoria, toda una novedad para la tradición savignana argentina, que conduce a la no aplicación del derecho normalmente competente por un criterio flexible otorgando facultades a los jueces, quienes deben ser cautelosos en la aplicación del criterio de los vínculos más estrechos para no lesionar la seguridad jurídica, la certeza, la uniformidad, previsibilidad y la cohesión e integración internacional.

\title{
ANALYSIS OF THE APPLICATION OF FOREIGN LAW IN LIGHT OF THE GENERAL PROVISIONS OF PRIVATE INTERNATIONAL LAW IN THE NEW ARGENTINE CIVIL AND COMMERCIAL CODE
}

\begin{abstract}
The New Civil and Commercial Code of the Argentine Nation, in force since august 2015, incorporated, in its articles, specific provisions of Private International Law-in Title IV of the Book Six-culminating a process of more than forty years responding to the need to legislate autonomously this branch of law recognizing its material autonomy, widely preached by national and international doctrine. The goal of the present work is to analyze the application of foreign law in the Argentine Civil and Commercial Code, as well as a brief relation to conventional source rules. Given the complexity, the exhaustively approach exceeds this article, therefore, it presents the two central aspects to be solved, the different doctrinal positions and their new treatment in the Argentine Legal System. The methodology used was based on the comparative analysis of the subject matter in Argentine and foreign doctrine and jurisprudence, its reception in the new Civil and Commercial Code, as opposed to its previous regulation and brief references to conventional source rules. Finally highlights the important contribution of this reform, the dialogue of sources and the reception of modern trends made flexible the rigid choice of the conflict rule.
\end{abstract}

Keywords: Civil and Commercial Code of the Nation - Private international Law - Foreign Law Application Exception clause 


\section{REFERENCIAS BIBLIOGRÁFICAS}

ARGENTINA. Códigos (2014) Código Civil y Comercial de la Nación. $1^{\circ}$ Edición. Ciudad Autónoma de Buenos Aires, Argentina: Infojus, 2014, 512 p.

Códigos (2014) Código Procesal Civil y Comercial de la Nación. Ciudad Autónoma de Buenos Aires, Argentina: Errepar, 2014,656 p.

Suprema Corte de la Provincia de Buenos Aires-SCBA. Banco de la Provincia de Buenos Aires c.

Melendi, Omar Darío y otra s/ cobro ejecutivo. 17 de diciembre de 2014. Recuperado el 5 de febrero de 2017, de: http://fallos.diprargentina.com/2015/06/banco-de-la-provincia-de-buenos-aires-c.html

Suprema Corte de la Provincia de Buenos Aires-SCBA. Soto, Javier c. EXXE S.A. 28 de abril de 2004 LLBA, 2004, 18-1318.

BATTIFOL, Henri; LAGARDE, Paul. Droit international privé. Tome I. $8^{\circ}$ Edición. París, Francia: Librairie genérale de droit et jurisprudence, $1995,656 \mathrm{p}$.

BIOCCA, Stella Maris; FELDSTEIN DE CÁRDENAS, Sara; BASZ, Victoria. Lecciones de Derecho Internacional Privado. Parte General. Segunda Edición. Buenos Aires. Argentina: Universidad, 1997, 213 p.

BOGGIANO, Antonio. Derecho Internacional Privado. En la Estructura Jurídica del Mundo. $6^{\circ}$ Edición Buenos Aires, Argentina: Abeledo Perrot, 2011, 840 p.

CALVO CARAVACA, Alfonso, CARRASCOSA GONZÁLEZ, Javier. Derecho Internacional Privado. $6^{\circ}$ edición. Volumen I. Granada, España: Comares, 2005, 736 p.

Derecho extranjero y recurso de casación (STS, Sala Primera, de 4 de julio de 2006): el Tribunal Supremo cruza el Rubicón. Anuario de Derecho Civil. Tomo LX, fasc. IV, España, 2007, p. 1843-1867, oct./ dic.

COMISIÓN EUROPEA. Red Judicial Europea en materia civil y comercial. Recuperado el 25 de noviembre de 2016 desde http://ec.europa.eu/civiljustice/applicable_law/applicable_law_spa_es.htm

Convención de Bruselas sobre el Canje de Publicaciones Oficiales y Documentos Gubernamentales entre Estados de 1958

Convención sobre el Reconocimiento y la Ejecución de las Sentencias Arbitrales Extranjeras de Nueva York, 1958

Convenio Argentino-Uruguayo sobre Aplicación e Información del Derecho Extranjero de 1980

DOS SANTOS, Olga. Hecho ilícito (tort) en el derecho norteamericano Revista de la Facultad de Ciencias Jurídicas y Políticas, $n^{\circ}$ 76. Universidad Central de Venezuela. 1990, p.233-272

FELDSTEIN DE CÁRDENAS, Sara. El Control de Constitucionalidad del Derecho Extranjero. Revista Electrónica del Instituto de Investigaciones "Ambrosio L. Gioja" -Año II, n 3, 2008, p.32-56

Reformas al Código Civil. Derechos Internacional Privado. Buenos Aires. Argentina: Abeledo Perrot, $1994,223 \mathrm{p}$.

FERMÉ, Eduardo. Derecho Internacional Privado -Convención Americana sobre Normas Generales. Enciclopedia Jurídica Omeba. Apéndice V. 1987, p.209-217. 
FERNÁNDEZ ARROYO, Diego. Argentina: comentarios sobre el nuevo derecho internacional privado para la República Argentina. 24 de octubre de 2014. Recuperado el 7 de junio de 2016, de https://cartasblogatorias.com/2014/10/29/argentina-observaciones-al-nuevo-dipr-para-la-republica-argentina/

FERNÁNDEZ ROZAS, José Carlos. Artículo 12, apartado 6 del Código civil: Aplicación judicial y extrajudicial del Derecho extranjero. In: ALBALADEJO, M; DÍAZ ALABART, S (Eds.) Comentarios al Código civil y Compilaciones forales. Tomo I, vol. 2 (973-1082) Madrid, España: Edersa, 1995.

FERNÁNDEZ ROZAS, José Carlos; SÁNCHEZ LORENZO, Sixto. Derecho Internacional Privado. $6^{\circ}$ Edición. Madrid. Argentina: Editorial Civitas, 2011,714 p.

FERREYRA, María, DE ROSAS, Pablo. El Código Civil y Comercial de la Nación y el nuevo derecho internacional privado argentino de fuente interna. Microjuris.com. 3 de febrero de 2016. MJ-DOC-7555-AR | MJD7555

FRESNEDO DE AGUIRRE, Cecilia Capítulo 6: Aspectos generales del sector del derecho aplicable. In: FERNÉNDEZ ARROYO, Diego (coord.) Derecho Internacional Privado de los Estados del MERCOSUR (pp.257-313). Buenos Aires, Argentina: Zavalía, 2003a, 1437 p.

Capítulo 28 Obligaciones extracontractuales. In: FERNÉNDEZ ARROYO, Diego (coord.) Derecho Internacional Privado de los Estados del MERCOSUR (pp.1157-1198) Buenos Aires, Argentina: Zavalía, 2003b, $1437 \mathrm{p}$

FRANCESCAKIS, Phocion. Quelques précisions sur les lois d'application inmédiate et leurs rapports avec les règles de conflict de lois. Revue Critique de Droit International Privé, París, Tomo LV, vol,1, 1996, p.55-65.

GOLDSCHMIDT, Werner. Derecho Internacional Privado. Derecho de la Tolerancia $7^{\circ}$ Edición. Buenos Aires, Argentina: Depalma, 1990, 823 p.

Introducción filosófica al Derecho - La teoría Trialista del mundo jurídico y sus horizontes. Buenos Aires, Argentina: Depalma, 1976, 665 p.

HENRÍQUEZ MAIONICA, Giancarlo. El control de la constitucionalidad del Derecho extranjero. Una perspectiva desde el Derecho venezolano. Revista Jurídica UCES, n 10, 2006, p. 191-225

HERRERA, Daniel; LAFFERRIERE, Jorge. Presentación In: LAFFERRIERE, J. (comp.) Análisis del proyecto de nuevo Código civil y comercial 2012: informe especial de la Facultad de Derecho de la Pontificia Universidad Católica Argentina. (pp.15-19) 1a ed. - Buenos Aires, Argentina: El Derecho, 2012, 695 p.

HERRERA, Marisa; CARAMELO, Gustavo; PICASSO, Sebastián. Código Civil y Comercial de la Nación Comentado. $1^{\circ}$ Edición. Tomo VI. Libro Quinto y Sexto. Ciudad Autónoma de Buenos Aires, Argentina: Infojus, 2015, $461 \mathrm{p}$.

JAYME, Erik. Identité culturelle et intégration: le droit international privé postmoderne. Cours général de droit international privé Recueil des cours, n²51, 1995, p.9-268.

KALLER DE ORCHANSKY, Berta. Nuevo Manual de Derecho Internacional Privado. $5^{\circ}$ Edición. Buenos Aires, Argentina: Plus Ultra, 1997, 644 p.

LAZCANO, Carlos. Derecho Internacional Privado. Buenos Aires. Argentina: Platense, 1965, 748 p. 
LORENZETTI, Ricardo (dir.) DE LORENZO, Miguel; LORENZETTI, Pablo. (coord.) Código Civil y Comercial de la Nación Comentado Tomo I. Buenos Aires, Argentina: Rubinzal-Culzoni, 2014, 908 p.

LORENZETTI, Ricardo; HIGHTON DE NOLASCO, Elena; KEMELMAJER DE CARLUCCI, Aida. Anteproyecto del Código Civil y Comercial. Fundamentos. 2012, 312 p. Recuperado el 12 de junio de 2015, de: http://www.nuevocodigocivil.com/wp-content/uploads/2015/02/5-Fundamentos-del-Proyecto.pdf

MEDINA, Graciela; RIVERA, Julio (dir.) ESPER, Mariano (coord.) Código Civil y Comercial de la Nación. Tomo VI. Comentario de ALL, Paula; ALBORNOZ, Jorge. Buenos Aires, Argentina: La Ley, 2014, 1026 p.

MENICOCCI, Alejandro. Codificación de Derecho Internacional Privado. Con especial referencia a la parte general y la regulación patrimonial en el proyecto de Código Civil y Comercial de la Nación. Anuario Argentino de Derecho Internacional XXIII, 2014, Córdoba Argentina, p.163-225

MERCOSUR. Acuerdo de Cooperación y Asistencia Jurisdiccional en Materia Civil, Comercial, Laboral y Administrativa entre los Estados Partes del MERCOSUR y la República de Bolivia y la República de Chile del 2002

MIAJA DE LA MUELA, Adolfo. Los Derechos Adquiridos en la Doctrina Española y en el Sistema de Derecho Internacional Privado Español. Anuario de Derecho Internacional, I, Universidad de Navarra, 1974, p.3-28

OEA. II Conferencia Especializada Interamericana sobre Derecho Internacional Privado Montevideo 1979 Protocolo Adicional al Tratado de Montevideo de 1889 Protocolo Adicional al Tratado de Montevideo de 1940

PARRA ARANGUREN, Gonzalo. El tratamiento procesal del derecho extranjero en los países de la América del Sur. Boletín de la Academia de Ciencias Políticas y Sociales, 1971, Caracas, vol. 32, n 47, p. $41-72$

PERUGINI ZANETTI, Alicia Panorama general del Capítulo I del Título IV del Proyecto de Código Civil y Comercial de la Nación. In: LAFFERRIERE, J. (comp.) Análisis del proyecto de nuevo Código civil y comercial 2012: informe especial de la Facultad de Derecho de la Pontificia Universidad Católica Argentina. (pp.659-684) la ed. - Buenos Aires, Argentina: El Derecho, 2012,695 p.

PORCELLI, Adriana. Regulación jurídica de los contratos internacionales en el Código Civil y Comercial de la Nación Revista Electrónica del Instituto de Investigaciones "Ambrosio L. Gioja" Año IX, n 15, 2015, p.79-121

Protocolo de Las Leñas de Cooperación y Asistencia Jurisdiccional en Materia Civil, Comercial, Laboral y Administrativa de 1992 con la reforma de 2002

RABINO, Mariela. La constitucionalización en el Derecho Internacional Privado Argentino. In: UZAL, María Elsa; NAJURIETA, María Susana (coord.) Derecho Internacional Privado (pp.3-33) la ed. Buenos Aires, Argentina: Abeledo Perrot, 2016,243p.

SCOTTI, Luciana; BRODSKY, Jonathan. Los Clásicos Problemas del Derecho Internacional Privado relativos al Derecho Aplicable en el Nuevo Código Civil y Comercial. En Letra, tomo 1, año 3, nº, 2015, p. 72-126 
SOTO, Alfredo. El Impacto del Nuevo Código Civil y Comercial en el Derecho Internacional Privado. Facultad de Derecho Universidad Nacional de Rosario [Archivo de video] 12 de febrero de 2016. Recuperado el 23 de agosto de 2016, de: https:/ /www.youtube.com/watch?v=7U1TuVeqoKw

TONIOLLO, Javier. Parte General del Derecho Internacional Privado en el Nuevo Código [Archivo de video] 25 de junio de 2015. Recuperado el 5 de octubre de 2015, de: https://www.youtube.com/watch?v=OWoeZojnopU

UZAL, María Elsa. Actualización Código Civil y Comercial Clase 20 Módulo IV. Colegio Público de Abogados de la Capital Federal [Archivo de video] 30 de junio de 2015. Recuperado el 20 de diciembre de 2015, de: http:/ $/$ www.cpacf.org.ar/noticia.php?id=3185\&sec $=118$

El pluralismo en el Derecho Internacional Privado como una necesidad Metodológica. El Derecho. Tomo 161, 1995, p. 1056-1063.

WEINBERG DE ROCA, Inés. Derecho Internacional Privado. Buenos Aires, Argentina: Depalma, 1997, 308 p.

Trabalho enviado em 23 de fevereiro de 2017.

Aceito em 28 de junho de 2017. 